\title{
The Host Defense of Drosopbila melanogaster
}

\section{Bruno Lemaitre ${ }^{1}$ and Jules Hoffmann ${ }^{2}$}

\author{
${ }^{1}$ Centre de Génétique Moléculaire, CNRS, 91198 Gif-sur-Yvette, France; \\ email: lemaitre@cgm.cnrs-gif.fr \\ ${ }^{2}$ Institut de Biologie Moléculaire et Cellulaire, UPR 9022 du CNRS, 67084 \\ Strasbourg Cedex, France; email: J.Hoffmann@ibmc.u-strasbg.fr
}

Annu. Rev. Immunol. 2007. 25:697-743

First published online as a Review in Advance on January 2, 2007

The Annual Review of Immunology is online at immunol.annualreviews.org

This article's doi:

10.1146/annurev.immunol.25.022106.141615

Copyright (c) 2007 by Annual Reviews.

All rights reserved

$0732-0582 / 07 / 0423-0697 \$ 20.00$

\section{Key Words}

insect immunity, Toll, Imd, recognition, pathogens

\begin{abstract}
To combat infection, the fruit fly Drosophila melanogaster relies on multiple innate defense reactions, many of which are shared with higher organisms. These reactions include the use of physical barriers together with local and systemic immune responses. First, epithelia, such as those beneath the cuticle, in the alimentary tract, and in tracheae, act both as a physical barrier and local defense against pathogens by producing antimicrobial peptides and reactive oxygen species. Second, specialized hemocytes participate in phagocytosis and encapsulation of foreign intruders in the hemolymph. Finally, the fat body, a functional equivalent of the mammalian liver, produces humoral response molecules including antimicrobial peptides. Here we review our current knowledge of the molecular mechanisms underlying Drosophila defense reactions together with strategies evolved by pathogens to evade them.
\end{abstract}




\section{INTRODUCTION}

AMP: antimicrobial peptide

RNAi: RNA

interference
Insects and microorganisms coexist within the biosphere in numerous ways. Frequently, insect larvae develop in decaying organic matter, and insect adults often serve as vectors for microorganisms causing plant and animal diseases. Thus insects have evolved sensitive mechanisms for recognition of pathogens and an array of strategies to defend themselves against attacks by bacteria, fungi, parasites, and viruses. To combat infection, the fruit fly Drosophila melanogaster relies on multiple innate defense reactions that are partially shared with higher organisms (1-4) (Figure 1). The mechanisms regulating these immune responses have been largely uncovered with the aid of genetic and molecular studies in Drosophila. The key role of the Drosophila model for studying immunity was illustrated by the initial genetic identification of signaling pathways mediating antimicrobial peptide (AMP) gene expression (5). Relatives of the Toll receptor protein, the cell surface receptor of the Drosophila Toll signaling pathway, also regulate innate immune responses in mammals. The conservation of a signaling pathway for the activation of antimicrobial defense responses suggests that some components of innate immunity share an ancient origin in metazoan evolution and demonstrates that Drosophila is a potent model for deciphering general innate immune mechanisms in animals. Investigations on the highly efficient immune reactions in this Dipteran insect have also provided information on other insects that have dramatic repercussions on human life as agricultural pests or as vectors for diseases such as malaria (e.g., the mosquito Anopheles).

The completion of the Drosophila genomic sequence in 2000 (6) and the subsequent expansion of new postgenomic technologies including proteomics, microarrays, and RNAi (RNA interference) have considerably widened the possibilities of immune system analysis in this model organism. This

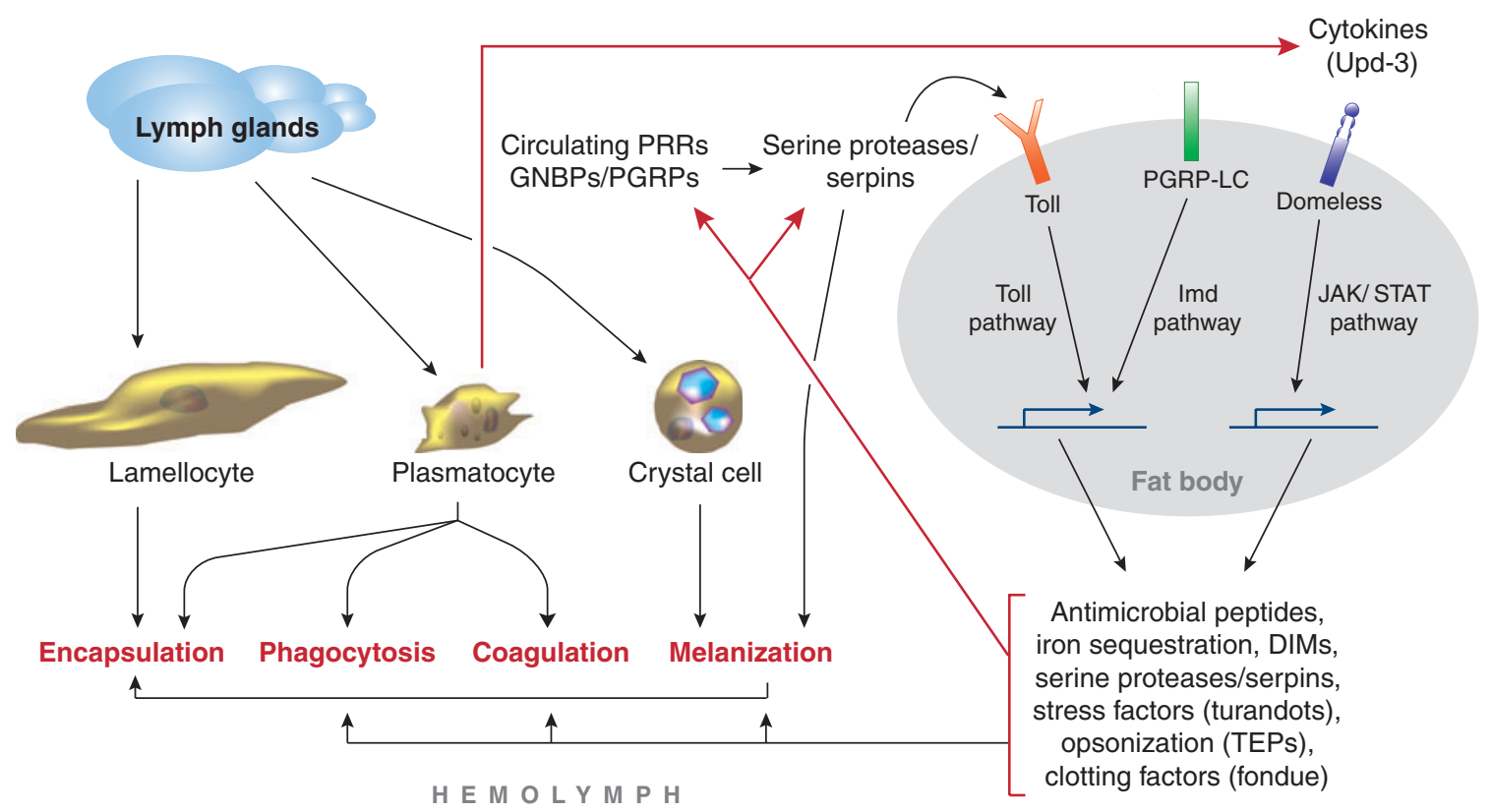

Figure 1

Schematic overview of Drosophila host defense. Detection of microbial pathogens elicits a large array of interconnected and synergistic defense modules in immune-responsive tissues. 
article presents an overview of our current knowledge of the Drosophila immune response in the context of two fundamental questions: (a) What are the molecular mechanisms underlying the defense reactions? (b) How does each of these mechanistic modules contribute to defense during an infection, and what strategies have been developed by the pathogens to evade them?

\section{REPERTOIRE OF DROSOPHILA DEFENSE MECHANISMS}

A hallmark of the Drosophila host defense, and that of most other holometabolous insects, is the challenge-induced synthesis and secretion of potent AMPs that accumulate in the hemolymph where they oppose invading microorganisms. Although synthesis of AMPs is probably common to all metazoans, secretion of these molecules into the hemolymph is not a general phenomenon. We refer it to as the "systemic immune response," which is by far the best analyzed among Drosophila immune reactions, and analyze it from the synthesis of immune effectors to recognition of infection. Epithelial immunity, i.e., the fight against invading microorganisms at the level of the barrier epithelia, is now understood to significantly contribute to the protection of Drosophila. This response is analyzed next both in terms of AMP and reactive oxygen species (ROS) production. A subsequent section deals with the cellular response by the hemocytes, especially their role in phagocytosis and encapsulation of parasites. The final section is devoted to two reactions, coagulation and melanization, which are activated immediately upon injury.

\section{The Systemic Immune Response}

Injection of bacteria into the body cavity induces the appearance of antimicrobial activity in the hemolymph of Drosophila. This activity persists for several days and can confer protection against a second challenge by pathogenic bacteria (7). This reaction mainly consists of
AMP production by the fat body, which is a major immune-responsive tissue that originates from the mesoderm during embryogenesis and acquires its immune competence at the onset of the first larval stage. Due to its large size and its location inside the open circulatory system of the insect body cavity, the fat body represents a powerful organ for the synthesis and secretion of peptides into the hemolymph, where they readily reach their effective concentrations.

Immune effectors. Among the various molecules produced by the fat body in response to infection, AMPs are the best characterized. Some 20 immune-inducible AMPs, which can be grouped into seven classes, have been identified (Figure 2). They are small $(<10 \mathrm{kDa})$, with the exception of the $25 \mathrm{kDa}$ Attacin, and cationic and exhibit a broad range of activities against bacteria and/or fungi (8). Diptericin, Drosocin, and Attacin are very effective against Gramnegative bacteria (9-11). Defensin is active against Gram-positive germs (12), whereas Drosomycin and Metchnikowin are antifungal agents $(13,14)$. Cecropin A1 acts against both bacteria and some fungi $(15,16)$. Defensins and Cecropins have been reported from many insects, whereas Drosomycin and Metchnikowin have so far been identified only in Drosophilidae (8). The insect AMPs are membrane-active, and their precise mode of action at the membrane level is still under investigation. Some AMPs are very stable owing to the presence of intramolecular disulfide bridges and are still detected in the hemolymph several weeks after challenge (17). Experiments with transgenic flies overexpressing a single AMP provided support for a critical role of AMPs in resistance to infection in Drosophila (18). However, the particular contributions of each of these AMPs have not been tested, as loss-of-function mutants for AMP genes are not available to date.

Recent large-scale analyses, at the transcriptome and proteome levels, have revealed that in addition to that of AMPs, the
ROS: reactive oxygen species 


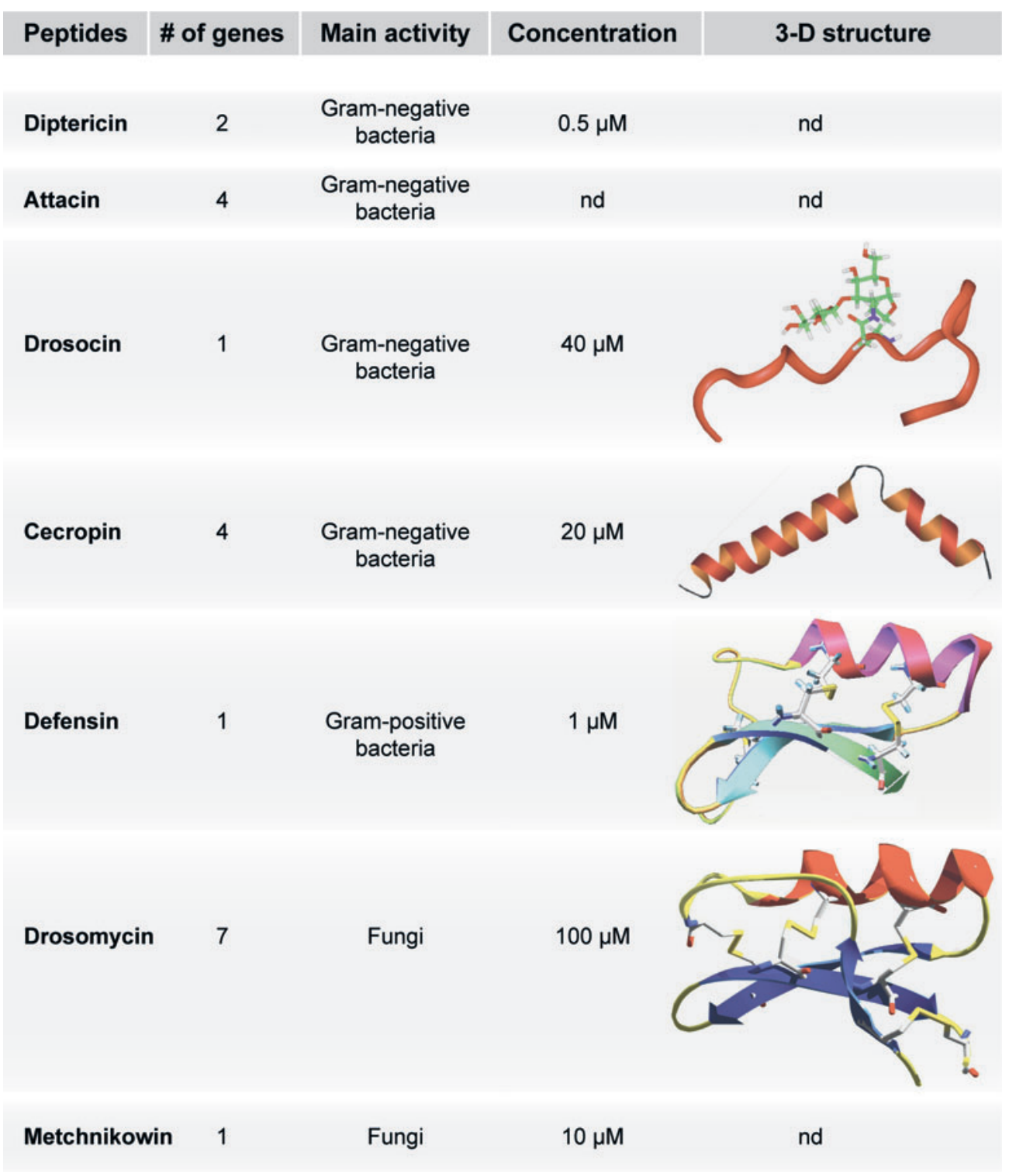

Figure 2

Drosophila antimicrobial peptides. Name, number of genes in the genome, antimicrobial activities, estimated concentration in the hemolymph after bacterial injection, and 3-D structure (8) (nd, not determined).

production of many peptides and proteins is upregulated after septic injury (19-25). ${ }^{1}$ Some of these are involved in the regulation of the

DIM: Drosophila immune molecule

\footnotetext{
${ }^{1}$ A list of all Drosophila immune genes can be found on the web at http://www.cgm.cnrs-gif.fr/immunity/ enindex.html.
}

systemic immune response itself (e.g., signaling components). Another group of proteins (opsonins, components of the melanization or clotting system) participates in distinct defense mechanisms, while an additional group includes putative immune effectors. Among these are 17 members of the DIM family 
(Drosophila immune molecule) and 8 Turandot proteins, which are small peptides of unknown functions secreted by the fat body $(17,25-$ 27). One catalase gene, two transferrin genes, and one iron transporter gene are also induced following septic injury, pointing to a role of ROS and iron sequestration in the control of microbial development $(19,28)$. Iron is essential for most invading microorganisms during the course of an infection, and both animals and plants have elaborated immune strategies that limit iron availability to the microorganisms.

Collectively, the systemic antimicrobial response represents a dramatic change in gene expression that not only results in the production of antimicrobial molecules in the hemolymph, but also participates in other immune mechanisms. Major challenges are to understand the relative contribution of these immune effectors to the total host defense, to test their specificity against certain pathogen classes, and to determine potential synergies between them.

Regulation. The massive expression of novel peptides/polypeptides that occurs following infection is primarily regulated at the transcriptional level. The cloning in the early 1990s of the genes in D. melanogaster that encode AMPs followed by promoter mapping experiments with the Cecropin $A 1$ and Diptericin genes revealed the presence of DNA motifs required for immune inducibility. These include a combination of NF- $\mathrm{kB}$ binding sites, GATA binding sites recognized by the transcription factor Serpent, and a less well-defined motif called R1 (29-33). Prominent among these motifs are the $\mathrm{kB}$ response elements, which confer immune inducibility (34-36). Three NF-kB/Rel-like proteins are encoded in the Drosophila genome. Dorsal and Dif, encoded by two clustered genes, contain an N-terminal Rel DNA binding domain and a C-terminal transactivator domain, whereas Relish is similar to mammalian p105, consisting of an N-terminal Rel domain and a C-terminal inhibitory ankyrin repeat domain (37-39a). Gel shift assays have shown that the three proteins (Relish, Dorsal, and Dif) bind to $\mathrm{KB}$ sites and can transactivate some of the AMP genes in cell culture $(37,38,40,41)$. Furthermore, genetic studies have demonstrated the key roles of these transactivators in the regulation of AMP genes via two distinct signaling pathways, referred to as Toll and Imd pathways.

The Toll patbway. The Toll pathway is an evolutionarily conserved signaling cascade that plays a key role in the establishment of the dorso-ventral axis of the Drosophila embryo, as well as in several other developmental processes (42). Canonic components of this pathway are the extracellular cytokine Spätzle (which shares structural similarities with the nerve growth factor, NGF), the transmembrane receptor Toll, the Tube and MyD88 adaptors, the Pelle kinase, Cactus (the Drosophila homolog of $\mathrm{I} \kappa \mathrm{B}$ ), and the Dorsal and Dif transactivators $(42,43)$ (Figure 3). Deletion of any of these components (except for Cactus and Dorsal) causes a similar immune-deficient phenotype characterized by the lack of expression of several immune genes, including the antifungal peptide Drosomycin gene, and a marked susceptibility to fungal and Gram-positive bacterial infection $(44,44 a)$. Dif and Dorsal seem to play redundant roles in the control of Drosomycin at the larval stage, whereas Dif is sufficient to mediate Toll activation in adults (45-47). Subtle roles for Dorsal have been proposed at the adult stage (48). Many components of the Toll pathway are themselves upregulated in a Toll-dependent manner upon infection $(44,49)$. The induction of the inhibitor molecule, Cactus, establishes a negative feedback on this cascade (50). Unlike vertebrate Toll-like receptors (TLRs), Toll does not function as a pattern recognition receptor but is activated by the cytokine Spätzle (44, 51, 52). The Drosophila genome encodes eight other Toll proteins, none clearly implicated in fly immunity $(53,54)$. The Drosopbila Toll pathway shares significant similarities 

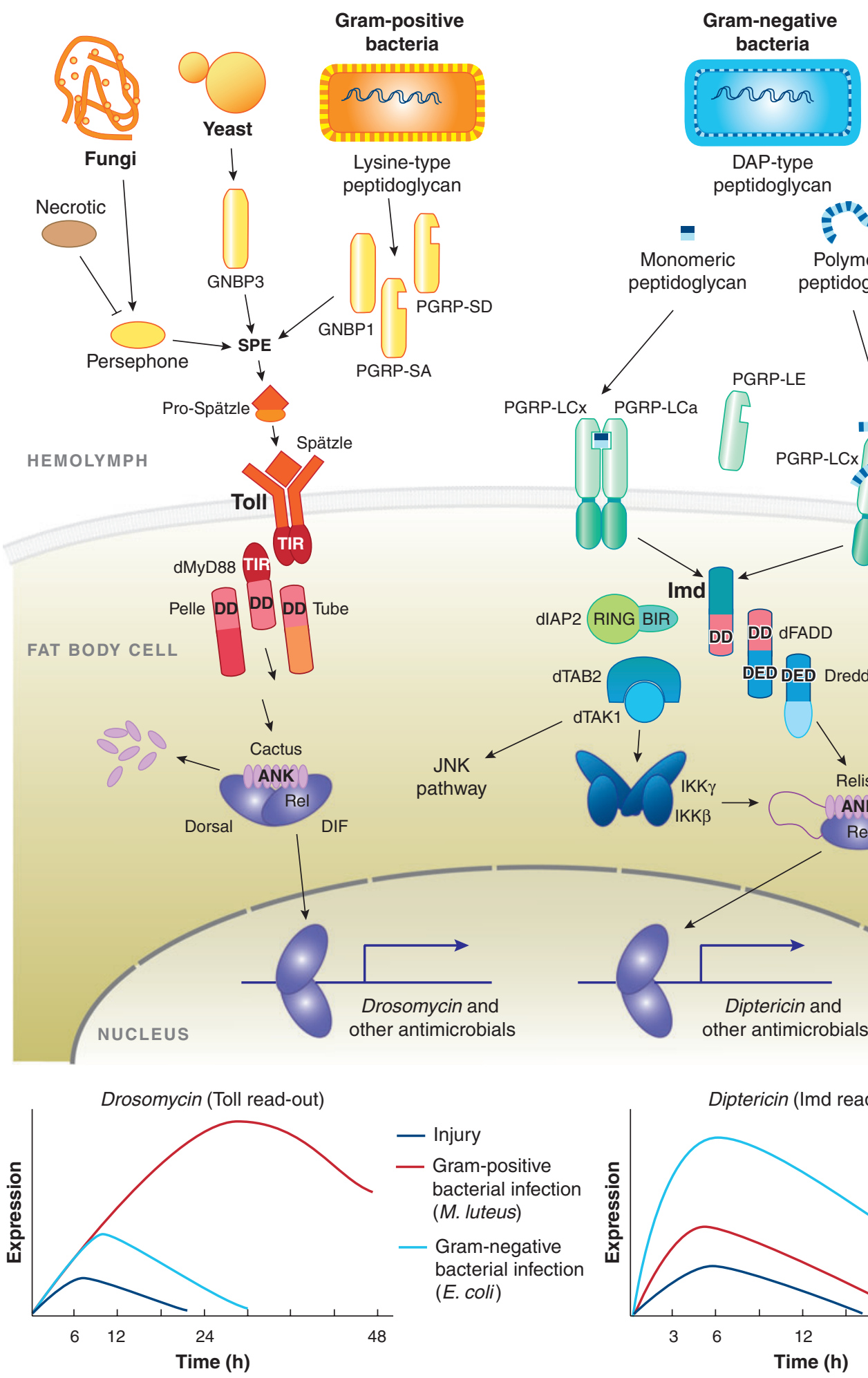
with the signaling cascade activated downstream of Interleukin-1 and the TLRs, pointing to a common ancestry of these immune mechanisms.

The Imd patbway. This pathway was initially defined by the identification of a mutation named immune deficiency (imd) that impaired the expression of several antibacterial peptide genes but only marginally affected Drosomycin induction (55-57). imd flies succumb to Gram-negative bacteria but are more resistant to fungi and Gram-positive bacteria than are Toll mutant flies. imd encodes a death domain-containing protein similar to that of Receptor Interacting Protein (RIP) of the tumor necrosis factor receptor (TNF-R) pathway, and its overexpression triggers the transcription/induction of antibacterial pep- tide genes in the absence of an infection (58). Genetic screens and reverse genetic approaches have led to the identification of eight additional canonical components of the Imd pathway: the PGRP-LC receptor (5961); the Mitogen-Activated Protein 3 kinase (MAP3K) TAK1 (62, 63); TAB2 (64-66); DIAP2, a member of Inhibitor of Apoptosis proteins $(64,65,67)$; IKK $\beta /$ ird5 and IKK $\gamma /$ Kenny, which form a Drosophila equivalent of the mammalian IKK signalosome (68$70)$; the dFADD adaptor $(71,72)$; the Dredd caspase (73); and the transcription factor Relish (74). Mutations affecting these factors generate an immune deficiency similar to that of imd. Noninfected imd-deficient flies are perfectly viable, and to date no developmental role has been attributed to this pathway. The Imd pathway shares some similarities

Figure 3

Model of Toll and Imd pathway activation. (Top) Antimicrobial peptide genes are regulated by a balance between two signaling pathways: the Toll pathway that is largely activated by fungi and Gram-positive bacteria, and the Imd pathway that is mainly activated by Gram-negative bacteria. According to the $\mathrm{kB}$ sites present in their promoters, antimicrobial peptide genes are more sensitive to either the Toll cascade (e.g., Drosomycin) or the Imd cascade (e.g., Diptericin) or are coregulated. Toll patbway: The Toll receptor is activated upon binding with a cleaved form of Spätzle that is processed by proteolytic cascades activated by secreted recognition molecules (PGRP-SA, PGRP-SD, GNBP1, GNBP3). Three distinct recognition modules that involve the sensing of Gram-positive bacteria (PGRP-SA, PGRP-SD, GNBP1), Glucan (GNBP3), and entomopathogenic fungi (via the direct cleavage of an SP) converge to the activation of SPE that cleaves Spätzle. Mature Spätzle binds as a dimer to Toll, thereby inducing its dimerization at the plasma membrane $(51,52)$. This causes the recruitment of three intracellular Death domain-containing proteins, MyD88, Tube, and Pelle, the latter also being a kinase (43). By a mechanism still uncharacterized, Cactus is phosphorylated, then degraded by the proteasome (50). As a consequence, the Rel transcription factors Dif and Dorsal are released and move from the cytoplasm to the nucleus $(37,142)$. Among the less well-understood aspects of this cascade are the respective roles of the multiple Spätzle isoforms, the mechanisms that link Pelle activation to Cactus degradation, and the complex regulation of Cactus isoforms. Imd pathway: Upon direct binding with bacterial elicitors (monomeric or polymeric DAP-type PGN), PGRP-LC recruits the adaptor Imd $(127,272)$. Imd then interacts with dFADD, which itself binds the apical caspase Dredd (273). This caspase has been proposed to associate with Relish, which it might cleave directly once Relish is phosphorylated $(274,275)$. After Relish cleavage, the Rel domain translocates to the nucleus, whereas the inhibitory domain remains stable in the cytoplasm. Relish is phosphorylated by the IKK signaling complex (68), which is itself thought to be activated by TAK1 and its adaptor TAB2 in an Imd- and possibly dFADD-dependent manner. The Ring domain protein DIAP2 may activate dTAK1. At present the mechanisms that link Imd to the IKK complex and the precise role of TAK1 and DIAP2 are not known (see text). TIR (Toll-IL1 receptor domain), DD (death domain), DED (death-effector domain), ANK (ANKyrin repeats), Rel (Rel homology domain), RING (RING finger domain), BIR (Baculovirus IAP repeat), SPE (Spätzle processing enzyme). (Bottom) Differential expression of Drosomycin (Toll target) and Diptericin (Imd target) genes in response to injection of E. coli (Gram-negative bacteria) or M. luteus (Gram-positive bacteria) (83). Diptericin shows an acute phase profile, whereas Drosomycin exhibits a late and sustained expression pattern.

TLR: Toll-like receptor

TNF-R: tumor necrosis factor receptor 


\section{MAPK:}

mitogen-activated protein kinase with the vertebrate TNF-R pathway. Several proteins were recently identified that affect the Imd pathway (64, 75-80a). The molecular organization of the Imd pathway is, however, as yet poorly defined owing to difficulties in performing epistatic analyses and to the absence of data on the subcellular localization of most of its components (Figure 3).

\section{Interactions between Toll and Imd pathways.}

To date, the Toll and Imd pathways are the sole reported intracellular cascades of Drosopbila that are activated by microbial ligands. Microarray studies using imd /Toll double mutant flies have shown that these cascades regulate almost $80 \%$ of the genes induced upon septic injury, reflecting their important contribution in survival from infection (49). An open question is whether the Toll and Imd pathways can synergize to increase the levels of induction of some of the immune-response genes, possibly via the formation of Dif/Relish heterodimers. Bioinformatic analysis has recently identified $\mathrm{\kappa B}$ binding sites specific for either Toll or Imd pathway activation (81). Although some immune-induced genes are clearly dependent on one pathway only (Diptericin for Imd, DIM1 for Toll), others can apparently be induced by both cascades. Most notably, Drosomycin, which is a convenient read-out for Toll pathway activation, receives a modest input from the Imd pathway in the systemic response and is solely activated by the Imd pathway in the local response $(73,82)$. The susceptibility of Toll and $i m d$ mutants to different classes of microorganisms is explained by the differential activation of these two pathways by distinct microorganisms as well as by the existence of specific immune target genes. Another important aspect of the antimicrobial response is the temporal activation of these two pathways. Genes regulated by Imd generally show an acute phase profile, whereas Toll target genes exhibit a late and sustained expression pattern $(21,47,83)$ (Figure 3).

Finally, a number of developmental and physiological factors affect Toll and Imd signaling by influencing the maturation of the fat body. This is reflected by the immune inducibility of Diptericin in larvae, which increases with age and is dependent on ecdysone, the key molting hormone of insects (84). All mutations affecting ecdysone metabolism can thus indirectly affect the immune response. This effect complicates immune studies and may explain a number of conflicting reports (85).

The $\mathcal{F A K / S T A T}$ patbway. The JAK/STAT pathway, originally identified through its role in embryonic segmentation, has three main cellular components: the receptor Domeless, the Janus Kinase (JAK) Hopscotch, and the STAT transcription factor (86). The first evidence for an involvement of the JAK/STAT pathway in insect immunity came from studies performed in the mosquito Anopheles indicating that after an immune challenge the STAT protein accumulates in the nucleus (87). Subsequent gene expression profile studies identified a subset of Drosophila immuneresponsive genes that are regulated by the JAK/STAT pathway, namely the genes encoding the complement-like protein Tep 2 and the Turandot stress genes $(21,88,89)$. Turandot are Drosophila-specific genes of unknown function that are induced by various stress conditions, especially by septic injury $(26,27)$. The transcriptional regulation of these genes is complex, with additional inputs from both the Imd and MAPK (mitogen-activated protein kinase) pathways (90).

JAK/STAT-deficient flies are as resistant to bacterial and fungal infections as are wild-type flies, and they express a normal AMP profile. They are, however, sensitive to infection with the Drosophila C virus (91). It has been proposed that the JAK/STAT pathway could respond to tissue damage and that a hemocyte-released cytokine, Unpaired-3 (Upd-3), activates this pathway by binding to the fat body Domeless receptor during infection (89). The precise role of this pathway and its overall contribution to the host defense remain to be established. 
Other pathways. The JNK pathway regulates many developmental processes in Drosophila and is required for proper wound healing of the epidermis $(92,93)$. Microarray analysis of S2 cells, a hemocyte-derived cell line, has shown that TAK1 activates the JNK pathway in response to bacteria via the JNK kinase basket (21). These data are consistent with a model where Imd signaling bifurcates downstream of TAK1, activating both JNK and IKK signaling (Figure 3). Some negative feedbacks between the Imd-Relish and ImdJNK branches have been reported $(94,95)$. In S2 cells, JNK-dependent immune genes encode many proteins involved in cytoskeleton remodeling, in keeping with a role in hemocyte activation (21). A role for the JNK pathway in AMP gene expression by the fat body has been proposed $(96,97)$.

The p38 stress pathway has been implicated in the immune response of plants, Caenorbabditis elegans, and mammals $(98,99)$. The Drosophila genome encodes two homologs of $\mathrm{p} 38$, and cell culture experiments identified several MAPKs acting upstream $(100,101)$. Although there is no in vivo evidence for a role of this pathway in the antimicrobial response, its implication in immune functions remains possible. Eiger/Wengen are Drosophila proteins with similarities to mammalian TNF and TNF-R, respectively $(102,103)$. Flies carrying a mutation in these genes are fully viable and do not display obvious immune defects. Overexpression of the eiger and wengen genes, however, leads to apoptosis via activation of the JNK pathway. The physiological function of these proteins has not yet been determined.

Microbial recognition. Injection of Grampositive or Gram-negative bacteria and fungi induces different patterns of AMP expression, indicating that microbial recognition mechanisms can differentiate between various classes of invaders (83). This property favors adapted effector responses via the selective activation of the Toll and Imd pathways. Microbial detection is a process that ultimately requires direct contact between a host protein called pattern recognition receptor (PRR) and a microbial molecule. Genetic studies have shown that microbial recognition acting upstream of the Toll and Imd pathways is achieved through peptidoglycan recognition proteins (PGRPs) and Gram-negative binding proteins (GNBPs), two families of PRRs initially identified in larger insects for their capacity to bind microbial ligands and to activate the proPO (prophenoloxidase) cascade (104-106).

Bacterial recognition by PGRPs. In Drosophila, recognition of bacteria is achieved through the sensing of specific forms of peptidoglycan (PGN) by PGRPs. PGN is an essential glucopeptidic polymer restricted to the cell wall of both Gram-negative and Gram-positive bacteria (Figure 4a). It consists of long glycan chains of alternating $\mathrm{N}$-acetylglucosamine and $\mathrm{N}$-acetylmuramic acid residues that are cross-linked to each other by short peptide bridges (107). PGN is a highly complex and fast-evolving molecule with marked differences from one bacterium to another. PGN from Gram-negative bacteria differs from most Gram-positive PGN by the replacement of lysine with meso-diaminopimelic acid (DAP) at the third position in the peptide chain. There is, however, a subclass of Gram-positive bacteria including Bacillus species, which produces DAP-type PGN. Another major difference between Gram-negative and Gram-positive PGN is its localization within the cell wall. Gram-negative PGN consists of a single layer and is hidden in the periplasmic space underneath the outer membrane and lipopolysaccharide (LPS) layer, whereas PGN from Gram-positive bacteria is multilayered and exposed at the bacterial surface.

The Imd pathway is activated by DAPtype PGN, whereas the Toll pathway is activated by Lys-type PGN, as demonstrated by studies using highly purified bacterial compounds (108). In contrast to vertebrates, LPS endotoxin, the major component of the
PRR: pattern recognition receptor

PGRP:

peptidoglycan recognition proteins

GNBP:

Gram-negative binding protein

proPO:

prophenoloxidase

PGN:

peptidoglycan

DAP:

meso-diaminopimelic acid

LPS:

lipopolysaccharide 
Gram-negative cell envelope, has no effect on Toll and Imd pathway activity, and previous positive results were explained by the presence of PGN contaminants in commercial LPS preparations (108, 109).
Further studies have demonstrated that both polymeric and monomeric DAP-type PGN can activate the Imd pathway. A specific monomer, GlcNAc-MurNAc(anhydro)L-Ala- $\gamma$-D-Glu-meso-DAP-D-Ala monomer, also known as tracheal cytotoxin (TCT), was

a

Glycan strand Lysosyme cleavage<smiles>COC(O)C(O)C(CO)OCCO</smiles>

\begin{tabular}{l|l} 
MurNAc & GIcNAC
\end{tabular}

GIcNAc MurNAc

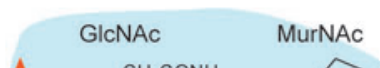

Anhydro bond found

Amidase

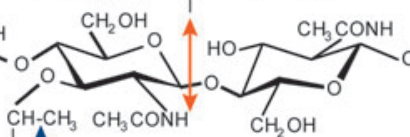
$\mathrm{CH}_{1} \mathrm{CH}_{3} \mathrm{CH}_{3} \mathrm{CONH}-\mathrm{CH}_{2} \mathrm{OH}$ PGRP cleavage $-\mathrm{CH}_{3}$

Short peptide bridge

b

Glycan strand
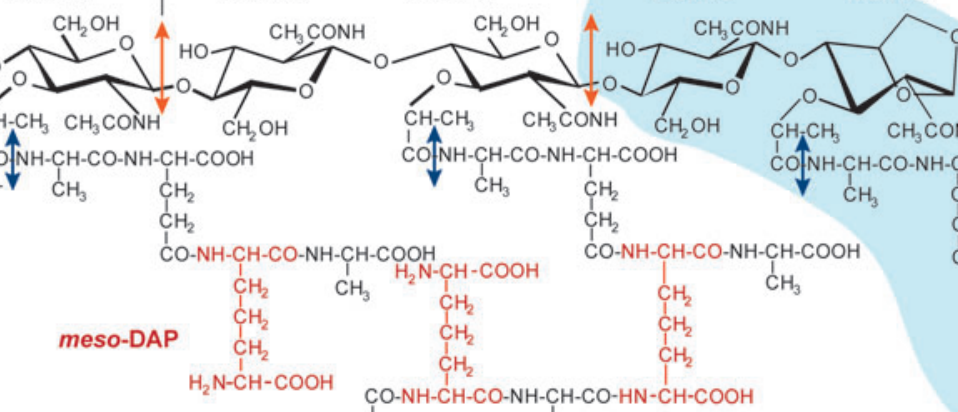

in the terminal PGN unit

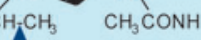
ONH-CH-CO-NH-CH-COOH

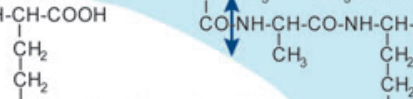

$\mathrm{CH}_{2}$ CO-NH-CH-CO-NH-CH-COOH
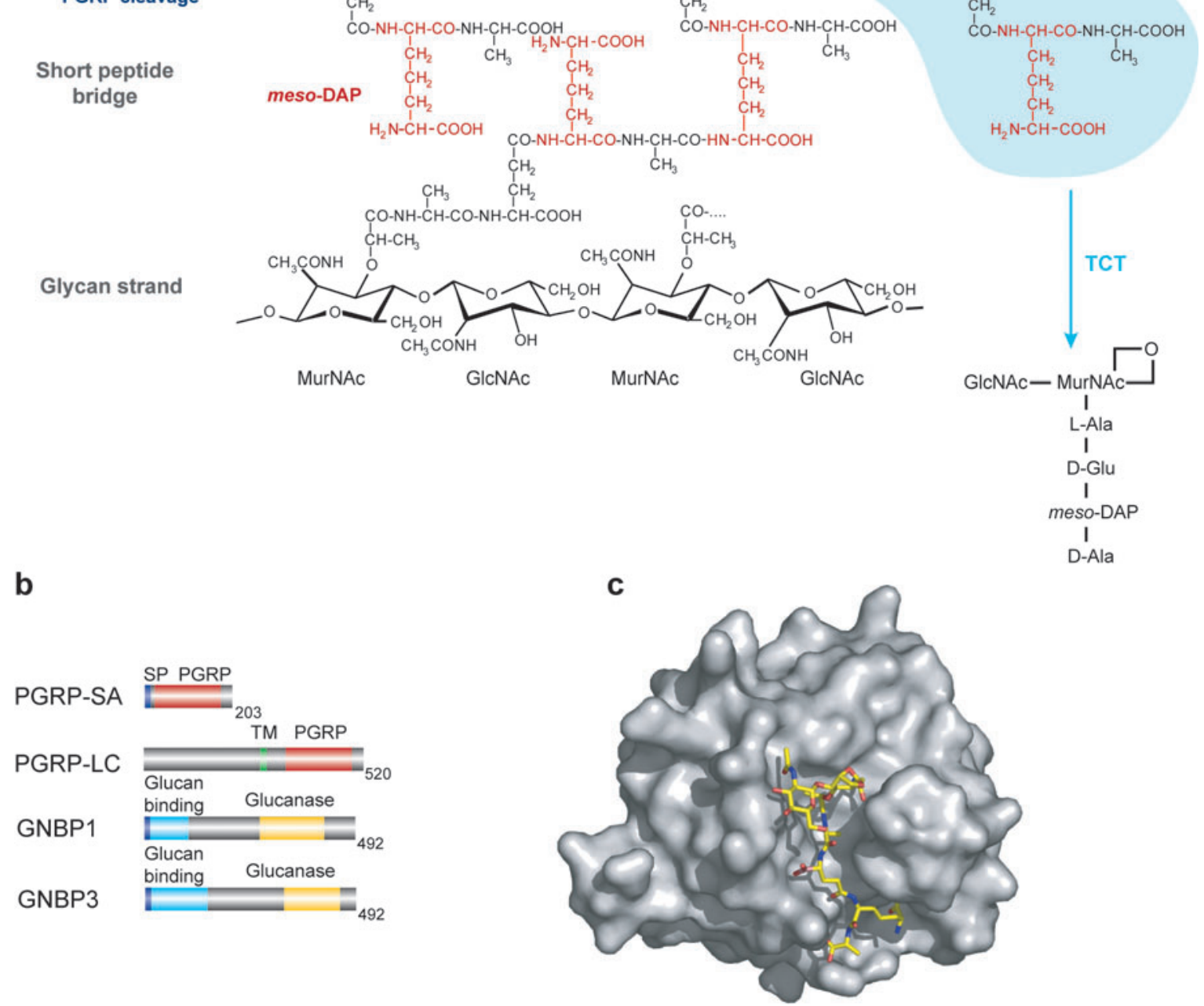
identified as the minimal PGN motif capable of efficient induction of the Imd pathway $(109,110)$. TCT provides an ideal "signature" of Gram-negative bacteria because this muropeptide is located at the end of the PGN strand and is released from PGN during cell growth and division (Figure $4 a$ ). In contrast, the minimum structure needed to activate the Toll pathway is a muropeptide dimer of lysinetype PGN (111).

PGRPs are highly conserved from insects to mammals and share a 160 amino acid domain (the PGRP domain) with similarities to bacteriophage T7 lysozyme, a zinc-dependent $\mathrm{N}$-acetylmuramoyl-L-alanine amidase (112114) (Figure $4 b$ ). Sequence analysis of the 13 Drosophila PGRPs points to the existence of two subgroups with either recognition or enzymatic properties. Members of the first group (PGRP-SA, SD, LA, LC, LD, LE, and LF) lack zinc-binding residues required for amidase activity but still retain the ability to bind and recognize PGN and function as PRRs. In contrast, proteins from the other subgroup of PGRPs, referred to as catalytic PGRPs, have demonstrated (PGRP-SC1, LB, SB1) or predicted (SC2, SB2) zinc-dependent amidase activity that removes peptides from the glycan chains, thereby reducing or eliminating the biological activity of PGN (115116a). Some of these PGRPs modulate the immune response by scavenging PGN (115117). The tertiary structures of four PGRPs have now been solved (118-123). A promi- nent feature is the presence of an extended surface groove in the PGRP domain, which includes a zinc-finger cage in the catalytic PGRP-LB. The structures of PGRP-LE and PGRP-LCa/ $x$ in complex with TCT show an interaction between the peptide stem of PGN and the PGRP groove (Figure $4 c$ ). In contrast to other PGRPs, the PGRP domain of PGRPLCa does not possess a typical PGN-docking groove, in agreement with its role as a coreceptor sensing monomeric DAP-type PGN (121).

Recognition of Gram-negative bacteria by PGRP-LE/LC. PGRP-LC-deficient flies display a strongly reduced expression of antibacterial peptide genes in response to Gram-negative bacteria. This effect is similar to, albeit weaker than, that observed for $i m d$ deficient mutants. Epistatic and phenotypic analyses indicated that PGRP-LC is the major receptor of the Imd pathway (59). Alternative splicing of PGRP-LC can produce three proteins ( $\mathrm{LCa}, \mathrm{LCx}, \mathrm{LCy}$ ) that share the same intracellular (signaling) domain but have distinct extracellular (sensing) domains $(109,112)$. Studies in cell culture using RNAi specific for each isoform have shown that PGRP-LCx is required for recognition of polymeric PGN, whereas both PGRP-LCa and PGRP-LCx are mandatory for detection of monomeric PGN (109). The current belief is that signaling is achieved by association of at least two PGRP-LC molecules in close

Figure 4

Recognition upstream of the Toll and Imd pathways. (a) Structure of E. coli PGN. PGN is a complex heteropolymer consisting of long glycan chains of alternating $N$-acetylglucosamine (GlcNAc) and $N$-acetylmuramic acid (MurNAc) residues, connected by short peptide bridges (107). All the terminal MurNAc residues ending the $E$. coli PGN glycan chains have a unique internal 1,6-anhydro bond. The TCT monomer (indicated in blue) occurs naturally in Gram-negative bacteria at the extremity of all glycan strands and is consequently present in approximately $5 \%$ of the GlcNAc-MurNAc units. Lysosymes catalyze the cleavage of the $\beta$-1,4-glycosidic bond between the MurNAc and GlcNAc residues (orange arrow) while amidase PGRPs remove the peptidic bridge from the sugar backbone (blue arrow). (b) Schematic structure of some PGRPs and GNBPs. SP, signal peptide; TM, transmembrane domain; PGRP, PGRP domain. GNPBs have an N-terminal domain that has been shown to bind $\beta(1,3)$-glucan and a C-terminal domain with homology to glucanase. (c) Three-dimensional structure of PGRP-LE with TCT (120). A prominent feature is the presence of an extended surface groove in the PGRP domain that interacts with the peptide stem of TCT (in color). 
proximity through binding of polymeric PGN. Such an interaction cannot occur with monomeric PGN, and in this case PGRP-LCa is expected to act as an adaptor $(121,124)$. This model is supported by the crystallization of TCT in complex with both PGRP-LCa and LCx (122).

PGRP-LE encodes a PGRP with affinity to DAP-type PGN and is expressed both extra- and intracellularly $(125,126)$. A fragment of PGRP-LE corresponding to the PGRP domain alone functions extracellularly to enhance PGRP-LC-mediated PGN recognition on the cell surface, a role evocative of that of mammalian CD14 in binding of LPS to TLR4 (127). A full-length form of PGRP-LE is also present in the cytoplasm and acts as an intracellular receptor for monomeric PGN, thus bypassing the requirement for PGRPLC (127). Monomeric PGN probably gains access to the cytoplasm by virtue of its small size. Thus, both PGRP-LC and PGRP-LE could participate in the sensing of Gramnegative bacteria upstream of the Imd pathway (Figure 3).

Downregulation of the Imd patbway by amidase PGRPs. Injection of Gram-negative bacteria induces a transient expression of antibacterial peptide genes (Figure 3), suggesting the existence of a mechanism to downregulate the immune response. Recent studies in Drosophila revealed a key role for amidase PGRPs in controlling the level of Imd pathway activity by degrading PGN $(116,117)$. PGRP-LB and PGRP-SC are efficient amidases that remove peptides from the glycan chains and thereby convert Gram-negative PGN into nonimmunostimulatory fragments. PGRP-LB is active only on DAP-type PGN, whereas PGRP-SC digests both DAP- and Lys-type PGN $(115,116)$. RNAi extinction of $P G R P-S C 1 / 2$ or $P G R P-L B$ leads to higher Diptericin expression after systemic infection compared to that of wild-type flies. PGRP-LB encodes a secreted protein and is regulated by the Imd pathway. The presence of PGRP-LB in the hemolymph establishes a negative feed- back loop that ensures an appropriate degree of immune activation in response to bacterial infection (116). This mechanism economizes host resources by anticipating the termination of the immune response. Amidase PGRPs may also prevent potentially severe consequences to host tissues through prolonged immune activity. In agreement with this idea, PGRP-SC1/2 RNAi larvae infected with bacteria showed increased lethality associated with developmental defects (117). The Drosophila genome encodes four other catalytic PGRPs. A combination of various amidase PGRPs likely ensures an adequate degree of immune reactivity in each fly tissue.

Recognition of Gram-positive bacteria. A mutation in PGRP-SA blocks the activation of the Toll pathway by Gram-positive bacteria but affects neither Toll activation by fungi nor Imd pathway activation by Gram-negative bacteria (128). PGRP-SA encodes a secreted PGRP, which is present in the hemolymph and acts upstream of Toll in the recognition of Lys-type PGN of Gram-positive bacteria (Figure 4b). Two additional proteins, GNBP1 (Gram-negative Binding Protein, in fact a historical misnomer) and PGRP$\mathrm{SD}$, have been implicated in the sensing of Gram-positive bacteria. The immune phenotype of loss-of-function mutations in GNBP1 is indistinguishable from that of $P G R P-S A$ mutations, and experimental data indicate that GNBP1 and PGRP-SA form a complex in the hemolymph $(129,130)$. A proposed function of GNBP1 would be to hydrolyze Gram-positive PGN into small fragments susceptible to detection by PGRP-SA (111, 130a). Some Gram-positive bacterial species such as Staphylococcus aureus can activate the Toll pathway in a PGRP-SA- and GNBP1independent manner, indicating that alternative receptors exist. Consistent with this hypothesis, PGRP-SD, yet another secreted PGRP, was found to mediate Toll activation by a subset of Gram-positive bacteria, in partial redundancy with the PGRP-SA/GNBP1 complex (131). 
Fungal recognition. Recent studies point to a role of GNBP proteins in the detection of fungal infection (81). Members of this family display a significant overall homology to bacterial glucanases (131a) (Figure 4b). They contain an $\mathrm{N}$-terminal domain that binds to $\beta(1,3)$-glucan and a C-terminal domain that is homologous to the catalytic domain of $\beta$-glucanase. However, the absence of conserved key residues in the catalytic site suggests that this domain is not functional. The Drosopbila genome contains three consensus members of the GNBP family and three related members containing only an $\mathrm{N}$-terminal domain similar to that of GNBP3. The GNBP3 protein sequence is highly similar to that of lepidopteran $\beta$ Glucan Recognition Proteins known to bind fungal $\beta(1,3)$ glucans (131b). A role of GNBP3 in fungal detection is supported by the observation that GNBP3 mutants are sensitive to fungal infection and fail to activate the Toll pathway (131c). According to this observation, GNBP3 is a circulating PRR acting upstream of the Toll pathway in fungal detection.

Activation of Toll by serine proteases. The Toll receptor is activated upon binding of a cleaved form of Spätzle (51, 52). The immune-induced cleavage of Spätzle is thought to be triggered by secreted PRRs that activate a proteolytic cascade, a process conceptually similar to vertebrate blood coagulation or complement activation cascades (132). These proteolytic cascades have a functional core consisting of several serine proteases (SPs) that undergo zymogen activation, followed by cleavage of a substrate by the terminal downstream protease. SP cascades allow the shaping and amplification of extracellular signals and are involved in complex regulatory mechanisms, in which inappropriate activation is prevented by the action of SP inhibitors (serpins) (133). The Drosophila genome encodes more than 200 SPs and serine protease homologs (SPHs), most of which have as yet uncharacterized functions (134). SPHs represent one quarter of all Drosophila
SP-related proteins and are thought to possess regulatory functions $(135,136)$. Many SPs that function in insect immunity contain a Clip-domain $\mathrm{N}$-terminal to the catalytic domain (137). This domain is only found in insect SPs and is believed to play a regulatory role in the sequential activation of SPs.

The activation of Spätzle during the immune response is achieved by a set of SPs distinct from those mediating Toll activation during embryonic development (44). Recent studies demonstrate the existence of a common core of SPs and SPHs acting upstream of Spätzle in the immune response that integrate signals sent by various secreted recognition molecules via more specialized SPs (138). SPE, an immune-regulated Clip-domain SP, has been identified as the Spätzle processing enzyme $(138,139)$. SPE presents $89 \%$ amino acid identity with Easter, the enzyme that processes Spätzle in the embryo. Toll activation by entomopathogenic fungi is independent of PGRP-SA, but is mediated by an extracellular cascade involving the Clip-SP Persephone (140) and the inhibitory serpin Necrotic (141). Overexpression of persephone or loss of function of necrotic is sufficient to trigger Spätzledependent activation of Toll in the absence of an immune challenge.

Recognition: concluding remarks. The past few years have seen the identification of the Drosophila PRRs regulating the Toll and Imd pathways and of the microbial ligands that they recognize. From an evolutionary point of view, it is interesting to note that insects use GNBPs and PGRPs as PRRs because these are proteins derived from enzymes known to degrade microbial cell wall products. Thus, the roles of these molecules may have evolved from microbicidal to recognition.

The organization of the Toll and the Imd pathways differs, in that the former is activated by secreted PRRs whereas the latter is activated through membrane-bound PRRs. This difference of architecture could reflect the mode of recognition: (a) direct for the Toll pathway for which PRRs can bind to
SP: serine protease

SPH: serine protease homolog 
microbial ligands exposed at the surface of Gram-positive bacteria and fungi, or $(b)$ indirect for the Imd pathway, which is activated by PGN released from the periplasm of Gramnegative bacteria.

Finally, it cannot be formally excluded that these pathways are activated through the recognition of host molecules (e.g., molecules released at the wound site). The existence of endogenous ligands is also supported by the observation that larvae with melanotic tumors display a significant AMP gene expression level in the fat body in the absence of an infection (142-144). One report suggests that endogenous DNA can activate the Imd pathway based on the observation that a fly line deficient in DNase II exhibits a higher Diptericin expression level in the absence of an infection compared to that of wild-type flies (145).

\section{Epithelial Immunity in Drosophila}

Because the barrier epithelia are in constant contact with large numbers of microorganisms, these surfaces must be armed with efficient systems for microbial recognition and control. This is especially true for insects such as Drosophila, which live on decaying matter and feed on fermenting medium. In Drosophila, both the gut and trachea, two main routes of infection, are lined with a chitinous matrix. Furthermore, the gut lumen is an environment hostile to microbial colonization due to its physical and physiological properties and the secretion of lysozymes $(146,147)$. In addition, local production of AMPs and ROS provides two complementary inducible defense mechanisms in the gut (Figure 5).

Local AMP expression. Expression of AMPs has occasionally been reported in epithelia of other insect species. In the silkworm larva Bombyx mori, Cecropin transcription is induced in the epithelial cells underlying the cuticle, when it is lightly abraded in the presence of live bacteria (148). In Drosophila, the use of GFP reporter transgenes has revealed that AMP genes are expressed in several surface epithelia that are in contact with the external environment $(82,149)$. These include the epidermis, the reproductive system, the respiratory tract, and the digestive tract. This AMP synthesis is referred to as the local immune response as opposed to the systemic response. One can distinguish between constitutive and inducible AMP expression in epithelia. In the first case, the AMP gene is expressed constitutively in a defined tissue, and its transcription is not upregulated during microbial infection. This is the case for Drosomycin in salivary glands and in the female spermatheca, and for Cecropin in the male ejaculatory duct (82). This constitutive expression is not regulated by NF- $\kappa \mathrm{B}$ pathways but by various tissuespecific transcription factors such as the homeobox-containing protein Caudal (150, 151). In virgin females, mating stimulates the expression of some AMP genes (152).

The second form is the inducible local AMP gene expression. This response is triggered upon natural infection by Gramnegative bacteria and is mediated by the Imd pathway $(82,153)$. For example, Drosomycin and Diptericin are induced in both trachea and gut via the Imd pathway in response to local infection by bacteria such as Erwinia carotovora (154). Like the systemic response, the local immune response is mediated through the recognition of Gram-negative PGN by PGRP-LC (116). It remains to be clarified why commensal bacteria or ingested PGN does not generate a state of permanent immune activation in tissues such as the gut. A central role in bacterial tolerance of the gut has been attributed to amidase PGRPs, as they scavenge PGN released by commensals $(116,117)$ (Figure 5). Because Gramnegative PGN is hidden in the periplasmic space underneath the outer LPS membrane and bacteria residing in the gut have a low division rate, commensals may well release only low amounts of PGN that can readily be hydrolyzed by amidase PGRPs. This implies the important concept of a threshold response for local immune activation in order to 


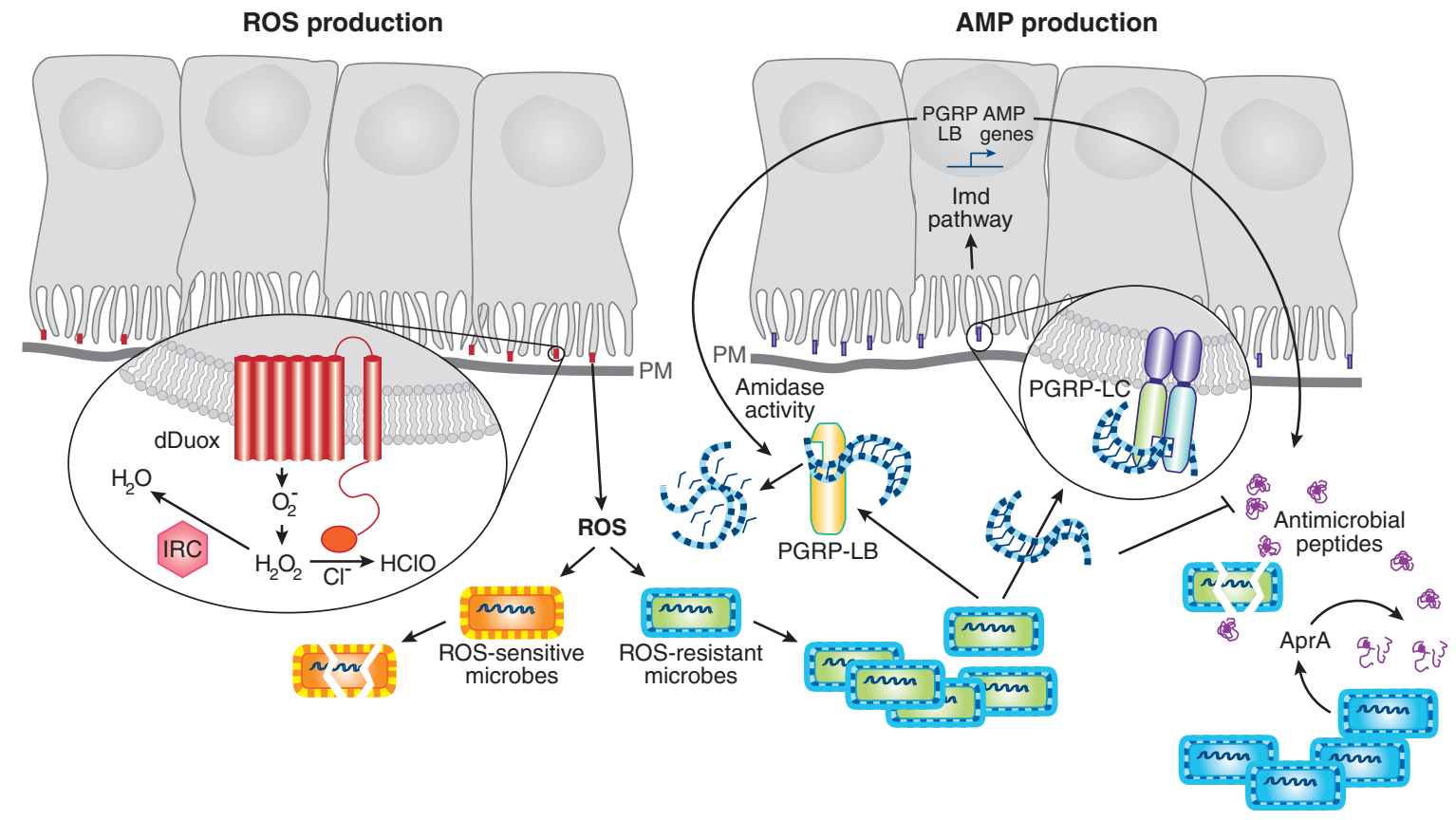

Figure 5

Gut immune response. Local production of ROS (left) and AMPs (right) provides two inducible defense mechanisms in the gut. ROS are produced by the Duox protein and are detoxified by the IRC catalase (156-158). Enzymatic assays demonstrated that the PHD domain of Drosophila DUOX can transform $\mathrm{H}_{2} \mathrm{O}_{2}$ into the highly microbicidal HOCl. AMPs (e.g., Diptericin or Attacin) are produced by epithelial cells under the control of the Imd pathway upon recognition of PGN released by Gram-negative bacteria $(116,117)$. Amidase PGRPs degrade PGN in nonimmunostimulatory fragments, thereby reducing the gut immune reactivity. Bacteria such as Pseudomonas entomophila secrete an abundant protease (AprA) that degrades AMPs (238). PM, peritrophic matrix.

differentiate between commensal microorganisms and invading pathogens.

To date, no implication of the Toll pathway in the local immune response has been demonstrated, and there is no evidence that AMPs are induced in epithelia in response to Lys-type Gram-positive bacteria or fungi.

ROS production. In mammals an immediate epithelial response to pathogen assault is the generation of ROS. In Drosophila, natural infections with bacteria also induce rapid ROS synthesis in the gut, and the dynamic cycle of ROS generation and elimination appears to be vital.

The Duox proteins form a conserved family of molecules that contain, in addition to the
NADPH domain, an N-terminal extracellular peroxidase domain (PHD) that can produce ROS in a regulated manner (155). Inactivation of the Duox gene by RNAi blocks ROS production in the gut of infected flies, suggesting that this enzyme is the sole source of epithelial ROS (156). Duox RNAi flies rapidly succumb to oral infection by the Gram-negative bacteria $E$. carotovora, and this lethality is associated with an inability to control bacterial growth. Excessive ROS production, which is deleterious to the host, is prevented in Drosophila by immune responsive catalase (IRC). Silencing of IRC by RNAi results in higher ROS production and fly lethality, indicating that IRC provides an antioxidant defense system in Drosophila (157). The IRC and Duox phenotypes demonstrate that a fine redox balance 

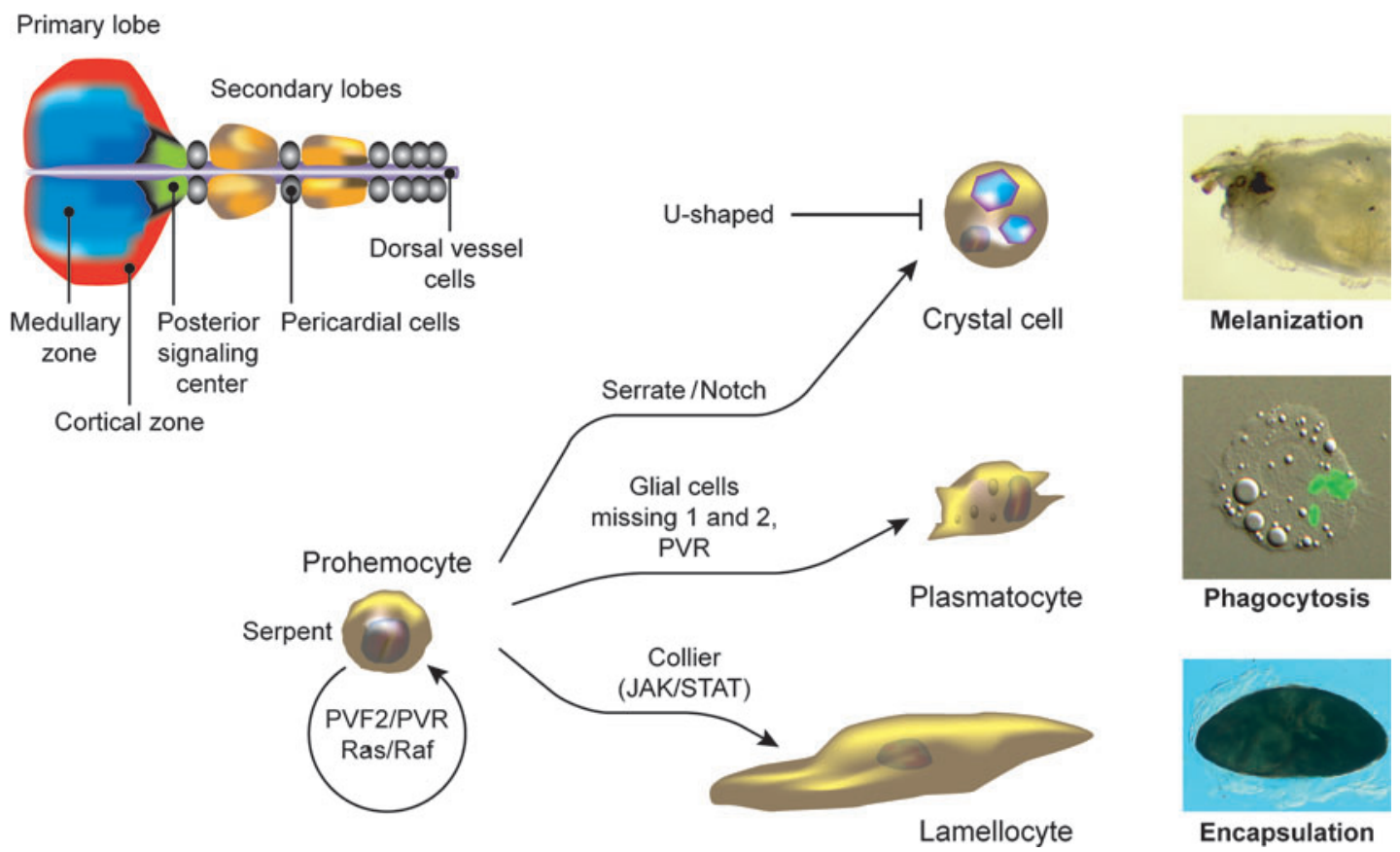

Figure 6

Drosophila hematopoiesis and hemocyte functions. The lymph gland contains a large number of hemocyte progenitors that can differentiate into three hemocyte types with distinct functions (indicated on the right). Many factors that regulate key steps of hematopoietic lineage commitment have been identified: serpent (GATA factor), U-shaped (Friend-of-GATA), Lozenge (Runx1 homolog), Glial Cells Missing 1 and 2, PVR (homologous to RTK receptors), and Collier (EBF ortholog) (164, 165, 193). Given their similarities to mammalian hematopoietic factors, these studies point to a conservation of molecular bases for blood-lineage determination in mammalian and Drosophila hematopoiesis. The JAK-STAT, Ras/Raf/MAPK, and Toll signaling pathways have also been implicated in hemocyte differentiation and proliferation, but their exact function is not yet known $(276,277)$.

is critical for control of microorganisms in the gut lumen. This ROS-dependent gut immunity is not affected by the Imd pathway and provides an additional barrier against ingested microorganisms (158) (Figure 5).

\section{Cellular Response}

The body cavity of Drosophila, like that of all arthropods, is filled with a circulating hemolymph that contains both free-floating and sessile blood cells (hemocytes). Drosophila larvae contain several thousand hemocytes, which can be divided into the following three cell types on the basis of their structural and functional features: plasmatocytes, crystal cells, and lamellocytes (Figure 6) (159,
160). Plasmatocytes represent $90 \%-95 \%$ of all mature larval hemocytes and function in the phagocytic removal of dead cells and microbial pathogens. Lamellocytes are relatively large, flat, and adherent cells that primarily function in encapsulation and neutralization of objects too large to be phagocytosed. Lamellocytes are not found in embryos and adults, and they are rarely observed in healthy larvae, although large numbers of these cells can be induced to differentiate from hemocyte precursors upon infection of larvae with parasitoid wasp eggs. Crystal cells constitute 5\% of the larval hemocytes and are nonphagocytic cells involved in the melanization process. Mature crystal cells express proPOs, which are oxidoreductases related to hemocyanins 
and which mediate melanization. They are fragile, readily disrupt, and release their contents into the hemolymph upon activation. They thus function as storage cells for the large amounts of proPO present in their cytoplasm in crystallized form (161).

Hematopoiesis. In Drosophila, mature plasmatocytes arise from two spatially and temporally distinct phases of hematopoietic development, one early in the embryonic head mesoderm and another during larval development in a specialized organ called the lymph gland (162-166). The embryonic phase of hematopoiesis gives rise to the mature circulating hemocytes of larval stages whereas lymph gland plasmatocytes, under normal, nonimmune conditions, do not enter circulation until metamorphosis. At the onset of metamorphosis, the lymph gland releases a large number of actively phagocytosing plasmatocytes, called pupal macrophages, which play a critical role in tissue remodeling as they phagocytose doomed larval cells. Once in circulation, these lymph gland-derived hemocytes, along with a subset of hemocytes derived from embryonic cells, persist into the adult stage. Many factors that regulate hemocyte differentiation and development have been investigated both at embryonic and larval stages $(164,165)$ (Figure 6). Recent studies have revealed that the primary lymph gland lobes are compartmentalized into three distinct zones: a posterior signaling center that acts as an organizer, a medullary zone containing hemocyte precursors, and a cortical zone containing differentiating hemocytes (Figure 6) $(167,168)$. The posterior secondary lobes serve as a reservoir for prohemocytes in a semiquiescent phase, but have a less well-defined organization than the primary lobes. Hemocyte proliferation is observed mostly in the cortical zone of the lymph gland and is barely detected among circulating cells. Both proliferation and differentiation can be modulated by developmental and immune stimuli. In the adults, lymph glands are absent and no hemocyte proliferation is observed, leaving a uniform population of several thousand mature plasmatocytes.

Blood cell immune functions. Phagocytosis and encapsulation are two major mechanisms of the cellular response.

Phagocytosis. In Drosophila, plasmatocytes are responsible for the disposal of both microorganisms and apoptotic cells. They can internalize a large variety of particles such as bacteria, yeast, Sephadex beads, doublestranded RNA (dsRNA), or ink particles within minutes. The first step of phagocytosis is the attachment of the phagocyte to the targeted particle, followed by cytoskeleton modification, internalization, and destruction of the engulfed target within phagosomes.

To date, phagocytosis has been shown to involve several types of receptor proteins. These include members of the scavenger receptor family (dSR-CI), the EGF-domain protein Eater, and the IgSF-domain protein Dscam (169-172). Proteins related to CD36 appear to favor phagocytosis, and two reports have proposed that PGRP family members could also play a role in this process (61, $173,174)$. The immune role of phagocytosis receptors is particularly well documented in the case of Eater, which is expressed exclusively on plasmatocytes (and prohemocytes) where it binds to and helps to internalize a broad range of bacteria (171). Importantly, Eater-deficient flies show a severe reduction of phagocytosis of Gram-negative and Grampositive bacteria. An LPS recognition protein (LRP) with six EGF repeats was recently identified in the beetle Holotrichia diomphalia (175). LRP is a protein that is secreted into the hemolymph and aggregates Gram-negative bacteria through its association with LPS. This points to the role of EGF-like repeatcontaining proteins to phagocytose and aggregate bacteria in insects.

The existence of entry receptors specific for certain pathogens is supported by the observation that knock-down of pestes, a member of the CD36 family of scavenger
dsRNA:

double-stranded

RNA 
TEP: thioester-containing protein receptors, blocks entry of $M$. fortuitum and $L$. monocytogenes in S2 cells, whereas it does not affect uptake of E. coli or S. aureus (176).

Another receptor that binds microorganisms and participates in phagocytosis is Dscam. It encodes a member of the Ig superfamily with essential function in neuron interconnection (172). The Dscam gene comprises a cluster of variable exons flanked by constant exons, which can theoretically generate by alternative splicing as many as 19,000 isoforms. Secreted isoforms of Dscam were detected in the hemolymph, and hemocytespecific Dscam silencing reduces the phagocytic uptake of bacteria. The molecular diversity of Dscam transcripts is highly conserved across major insect orders, pointing to a conserved role of this gene.

Systematic RNAi screens in S2 cells identified many Drosophila genes required for the internalization of various microorganisms (61, 176-179). As expected, a large number of these genes affect actin cytoskeleton organization (cdc42, Arp2/3complex, actin capping proteins, cofilin) and vesicle trafficking as well as other essential cell functions. Among the rare in vivo studies, a genetic analysis has clearly demonstrated a role for the WASp homolog D-Scar in phagocytosis, while Chickadee, the Drosophila homolog of the G-actin sequestering protein Profilin, negatively regulates this process (180). The observation that phagocytosis was only reduced by $40 \%$ in $D$ Scar flies underlines the complexity of the phagocytosis process, and the possibility that multiple internalization pathways coexist in Drosophila hemocytes.

In mammals, the engulfed target is destroyed within phagosomes by lysosomal enzymes, ROS, and nitric oxide as well as antimicrobial factors such as defensins. The mechanisms that kill the microorganisms inside the vacuoles have been poorly investigated in Drosophila. DNase II enzymes are highly conserved proteins that are required for the degradation of DNA within phagolysosomes. Flies depleted in DNase II show an increased susceptibility to infection with both Gram-positive and Gram-negative bacteria, although this phenotype could not be definitely linked to a phagocytosis defect (181).

Opsonization. The Drosophila genome harbors six genes coding for proteins structurally related to the complement alpha2macroglobulin family (88). Five of these genes contain a canonical thioester motif and are referred to as thioester-containing proteins (TEP1 to TEP5); the sixth member, TEP6 or Mcr (Macroglobulin-complement related), lacks the cystein residue that forms the characteristic thioester of TEPs. The TEP family members possess a signal peptide indicating that they are secreted, and three of them, TEP1, TEP2, and TEP4, are upregulated upon infection (88). It has been proposed that TEPs function during the immune response as opsonins to promote phagocytosis and/or protease inhibitors. An opsonin function for a TEP member has been documented in Anopheles gambiae where TEP1 is also involved in parasite killing of Plasmodium (182). Recently, the contribution of Drosophila TEPs to phagocytosis has been investigated in S2 cells using RNAi (178). TEP2 and TEP3 are required for efficient phagocytosis of the Gram-negative bacteria E. coli and the Grampositive bacteria Staphylococcus aureus, respectively, and Mcr for successful binding to the surface of C. albicans and for efficient internalization of this fungus. Other opsonization factors could be secreted isoforms of Dscam or so far uncharacterized proteins related to the LRP of $H$. diomphalia.

Encapsulation. Encapsulation is a dramatic defense reaction against invading parasites that is mediated by lamellocytes in Drosophila larvae. The encapsulation reaction has essentially been analyzed using wasps that lay their eggs into the hemocoel of larvae, but it can also be induced by the injection of an oil droplet (Figure 6, and see Figure $8 \boldsymbol{b}, \boldsymbol{c}$ ) $(165,183)$. The wasp egg is detected by plasmatocytes, which exert a permanent immune 
surveillance in circulation (184). They attach to the egg chorion and induce within a few hours, through unknown signaling molecules, a strong cellular reaction in the lymph gland, with an increase in proliferation and the massive differentiation of lamellocytes from prohemocytes of the medullary zone and secondary lobes (168). Lamellocytes are released from the lymph gland and then form a multilayered capsule around the invader, a process that is ultimately accompanied by blackening of the capsule due to melanization. Within the capsule, the parasite is eventually killed, possibly by the local production of cytotoxic products such as ROS and intermediates of the melanization cascade (185), but the exact cause of death is not known. The molecular mechanisms underlying the whole process of encapsulation are virtually unknown. Use of thermosensitive alleles of the myospheroid gene, which encodes an integrin subunit, reduced the efficiency of capsule formation without affecting lamellocyte differentiation. A role for integrins in this process is not unexpected as lamellocytes aggregate and stick together through septate junctions in order to build a capsule (186). This is further supported by studies in Lepidoptera (187). Two members of the Rho GTPase family, Rac1 and Rac2, which regulate many aspects of cytoskeleton remodeling, have also been shown to participate in this process. In Rac $2 \mathrm{mu}-$ tants, plasmatocytes adhere to the parasitoid egg but fail to spread, and septate junctions do not assemble, possibly due to defective localization of the Protein 4.1 homolog Coracle (188). Rac1 and the Jun Kinase Basket regulate the formation of actin- and focal adhesion kinase (FAK)-rich placodes in hemocytes and are both required for the proper encapsulation of parasitoid wasp eggs (189). Hemese is a transmembrane glycophorin-like protein with an expression restricted to the cell surface of hemocytes and to the hematopoietic organs (190). Depletion of Hemese by RNAi has no obvious effect under normal conditions, but the cellular response to parasitic wasps is much enhanced, suggesting a mod- ulatory role in the activation or recruitment of hemocytes. Microarray analysis identified many genes whose expression is upregulated after wasp infection. These genes are promising candidates for the analysis of the encapsulation process (191).

Encapsulation is a fascinating immune reaction that requires communication between distant organs and involves different hemocyte lineages. The mechanism by which the wasp eggs are recognized by the Drosophila immune system is not known. Since parasitoids and Drosophila are phylogenetically related, wasp eggs may not be easily detected through PRRs in contrast to fungi or bacteria. Early experiments showed that Drosophila larvae encapsulate transplanted tissues from the same species when they are mechanically damaged. Tissue fragments with intact basement membrane remain free in circulation (192). This suggests that the destruction of the basement membrane is sufficient to induce an encapsulation reaction. Hemocytes could recognize intruders due to the absence of a factor found on their own basement membrane. A further question is the nature of the signaling molecules that trigger lamellocyte differentiation within the lymph gland. An attractive hypothesis holds that upon sensing the wasp egg, plasmatocytes send a cytokine to the posterior signaling center in the lymph gland to induce lamellocyte specification in neighboring cells (193).

Melanotic pseudotumors. The melanotic pseudotumor-or melanotic tumor-phenotype is characterized by the presence of black bodies either free-floating within the body cavity, or attached to internal organs (194, 194a). These noninvasive pseudotumors are rare in wild-type flies but can be frequent in some genetic backgrounds. Melanotic capsules share many features with capsules that form around a parasite, as they contain layers of melanized lamellocytes. Watson has proposed a distinction between two types of melanotic tumor mutants (195). Class 1 includes mutants in which melanotic tumors 
result from an "autoimmune response" or the response of an apparently normal immune system to an abnormal target tissue. It was proposed that disruption of the basement membrane that lines tissues could lead to melanotic tumors by inducing hemocyte adhesion and capsule formation (192). Class 2 mutants display overactivation of hemocytes resulting in the formation of capsules. Many mutations known to activate the fly immune system (such as Toll and JAK gain-of-function mutations) belong to this class $(142,196)$.

Other hemocyte immune functions. Like the fat body, hemocytes store various molecules that can be released upon infection. Plasmatocytes express immune molecules such as the blood clotting factor Hemolectin or the Toll ligand Spätzle, whereas crystal cells contain the enzymes required for the melanization cascade $(161,186,197)$. Circulating plasmatocytes express many components of the extracellular matrix (Collagen IV, Peroxidasin, etc.) and may contribute to the formation of basal membranes (198).

Septic injury also triggers the expression of antibacterial peptide genes via the Imd pathway in a subset of circulating plasmatocytes (199). Their contribution to hemolymph antimicrobial activity is probably minimal. Both S2 and mbn-2 cell lines that derive from hemocytes express AMP genes in the presence of Gram-negative PGN and Drosomycin in response to Spätzle $(43,110,200)$. In these cells, the Imd pathway also activates the JNK pathway that may participate in hemocyte activation through cytoskeleton remodeling (21, 96).

Hemocytes are believed to play signaling functions between distant immuneresponsive tissues, in particular via the production of cytokines (e.g., Upd-3) (89).

\section{COAGULATION AND MELANIZATION}

Physical breakage of the arthropod cuticle immediately induces hemolymph clotting and melanization. Although these reactions are well characterized in other arthropods (201, 202), progress in our understanding of these reactions in Drosophila has been made only recently.

\section{Coagulation}

Clotting is critical in limiting hemolymph loss and initiating wound healing in insects as in vertebrates. It is also an important immune defense, quickly forming a secondary barrier to infection, immobilizing bacteria and thereby promoting their killing. In Drosophila larvae, a clot composed of fibers trapping hemocytes is rapidly generated at the site of injury (Figure $7 a, c)$. This reaction is independent of melanization because it still occurs in proPO-deficient mutants (see below) (203). It is, however, assumed that crosslinking enzymes, including proPO itself and transglutaminase, may be involved in hardening of clots (204, 205). Subsequent steps in wound closure include melanization and epithelial movements (Figure 7c) $(92,93)$. One plasmatocyte-specific gene, bemolectin, has been demonstrated to be required for efficient clot formation in Drosophila $(197,203)$. Hemolectin is a large protein with several domains that are also present in other clotting factors (Figure 7b). It is a major component of the fibers (Figure $7 \boldsymbol{b}$ ). A pulldown assay and proteomic studies have identified additional proteins present in the clot $(203,204)$. One of these, Fondue, is an abundant hemolymph protein regulated by the Toll pathway, which exhibits multiple repeat blocks. Depletion of fondue by RNAi induced clotting defects (144). Fondue is not involved in the formation of primary clot fibers, but rather in the subsequent cross-linking of these fibers. Wounding of fondue-RNAi or bemolectin larvae or flies does not lead to increased mortality compared to challenged controls. Thus it appears that impairment of clotting in vivo leads to more subtle phenotypes, such as the formation of larger scabs $(144,203)$. 

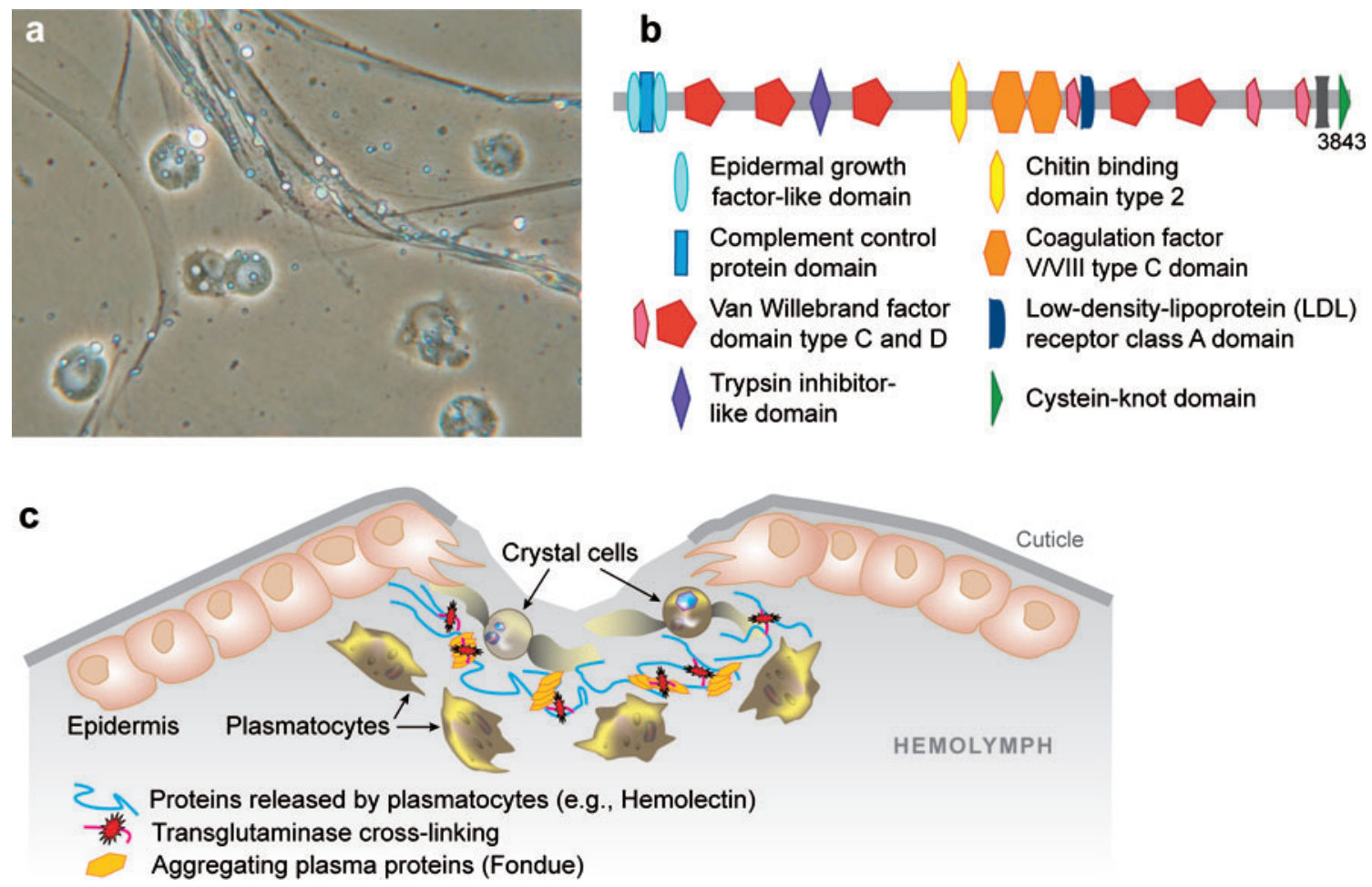

Figure 7

Clotting reaction in Drosophila. (a) A Drosophila clot with fibers and incorporated plasmatocytes. (Courtesy of Ulrich Theopold, Stockholm University.) (b) Structure of Hemolectin. Hemolectin is a large protein with domains that are also present in other clotting factors (197). Hemolectin is a major component of Drosophila clotting fibers. This figure was done using the SMART bioinformatic tool (EMBL, Heidelberg) for identifications and positions of domains. (c) A model for clot formation at an injury site. Upon injury, plasmatocytes immediately release Hemolectin and other proteins that form clot fibers. Cross-linkage of these fibers occurs with the help of proteins such as Fondue, transglutaminase, and proPO, the latter being released by crystal cells.

\section{Melanization}

An immediate immune response in Drosophila is the melanization reaction observed at the site of cuticular injury or on the surface of parasites invading the hemocoel (Figure 6). This blackening reaction results from the de novo synthesis and deposition of melanin. It is generally assumed that melanization plays an important role in arthropod defense reactions such as wound healing, encapsulation, sequestration of microorganisms, and the production of toxic intermediates that are speculated to kill invading microorganisms (206-208). Melanization requires the activation of proPO, an enzyme that catalyzes the oxidation of mono- and diphenols to orthoquinones, which polymerize nonenzymatically to melanin. Enzymatically inactive proPO is cleaved into active phenoloxidase (PO) by an SP known as prophenoloxidase activating enzyme (PPAE). PPAE also exists as an inactive zymogen that is itself stimulated through a stepwise process involving other SPs. Studies with other insect species indicate that the melanization cascade is triggered by injury or by recognition through PRRs of microbial ligands, such as PGN, $\beta(1,3)$-glucan, and LPS (209-212). Consequently, the proPO cascade is an efficient nonself-recognition system in invertebrates.
PO: phenoloxidase

PPAE:

prophenoloxidase activating enzyme 
The Drosophila genome encodes three proPOs: DoxA1, DoxA3, and CG8193. DoxA1 and $C G 8193$ are expressed in crystal cells while DoxA3 is exclusively expressed in lamellocytes and as a consequence may participate in melanization during encapsulation (186). Melanization at injury sites in larvae is mediated exclusively by crystal cells and is impaired in three classical hemocyte mutants: domino, which lacks hemocytes (213); Black cells, which has aberrant crystal cells; and lozenge, which lacks crystal cells (161). None of the classical immune pathways (Toll, Imd, JAK-STAT) is involved in the rapid release of PO by crystal cells, but the rupture of crystal cells and subsequent melanization are blocked when the function of the RhoA GTPase is altered (81). The source of PO in adults that are devoid of crystal cells is not known. Recently, two Clip domain-containing SPs, MP1 and the crystal cell-specific MP2/sp7/PAE, and one serpin, Serpin27A, have been implicated in the melanization cascade (143, 214-217). Inactivation of MP1 and MP2 reduces the level of PO activity after immune challenge, while excessive melanization is observed in Serpin27A-deficient mutants. The role of Serpin27A is to restrict melanization to the site of injury and prevent systemic melanization. These analyses also suggest that MP1 is involved in the defense against both bacteria and fungi, whereas MP2 is more specific for the antifungal response (217). Except for these reports, our information on the organization of proteolytic cascades that regulate proPO activation is still scarce, and a possible link with PRRs remains to be established.

\section{DROSOPHILA IMMUNITY AND PATHOGEN EVASION STRATEGIES}

Immune defense mechanisms are selected for their capacity to confer resistance to microorganisms and parasites encountered in the wild. Their organization somehow reflects the evolution of interactions between the host and its pathogens. It is therefore important to un- derstand how an immune system works in response to its pathogens and the diseases they inflict on the host. A major difficulty for a detailed understanding of the fly immune system is our ignorance of the impact of various pathogens on Drosopbila populations. This situation is complicated by the fact that $D$. melanogaster belongs to a fruit fly species that recently spread across the world and is often associated with human habitats. This broad ecological niche does not help to narrow down the list of natural Drosophila pathogens and their effects. However, a number of Drosophila pathogens have been identified in laboratories or in the wild (218), some of which are currently used to analyze the immune response under more physiological conditions.

In the second section of this review, we first describe various infection models used to study Drosophila immunity and then discuss the evasion strategies developed by pathogens to escape the immune response, thereby revealing the complexity of host pathogen interactions in an insect model.

\section{Immunity to Bacteria}

Immunity to septic injury. Our knowledge of the Drosophila immune response is essentially based on the analysis of host reactions following injection of nonpathogenic bacteria (e.g., E. coli or Micrococcus luteus) either by pricking the body wall with a sharp needle coated with bacteria or by the microinjection of a precise dose of microbes directly into the body cavity of the insect. As discussed above, directly introducing a microorganism into the hemocoel triggers a rapid response that allows monitoring of the multiple facets of the interactions between a microorganism and the systemic immune defense (219). The expression of AMP genes is usually proportional to the number of bacteria injected and reaches a plateau or even decreases when flies are injected with massive doses of bacteria (108). There is no equivalent of an overactive inflammatory response in adult Drosophila comparable to the septic shock in mammals, and 
flies are resistant to injection of large amounts of bacteria such as $E$. coli.

Mutations affecting the Imd or the Toll pathways cause the most severe immune deficiency to bacterial challenge, and death is always associated with excessive bacterial growth (44). Death of the host usually occurs when numbers of bacteria increase beyond $10^{6}$ per fly. Inhibition of phagocytosis through injection of Sephadex beads that saturate the plasmatocytes has no effect in wildtype adults but increases the susceptibility of imd mutant flies to E. coli (220). Similarly, an effect of melanization against bacteria can be detected when a mutation affecting this process is combined with Toll or Imd pathway mutations $(55,217)$. Survival experiments in larvae carrying combinations of mutations affecting hemocytes (domino), the antibacterial response $(i m d)$, and melanization (Black cells) after an immune challenge with $E$. coli establish the relevance of all three immune reactions in larvae-AMP production, phagocytosis, and melanization — and point to a synergy between them to fight infection (213).

Two fast killers: Pseudomonas aeruginosa and Serratia marcescens. Unlike the situation described above, injection of a small number of cells of Pseudomonas aeruginosa or Serratia marcescens into the hemolymph is fatal to wild-type flies $(7,221-223)$. Both bacteria are opportunistic and versatile pathogens that have developed the ability to adapt to a large number of environmental conditions. The reasons why these two bacterial species are so pathogenic to flies are not clearly established. Following injection, $P$. aeruginosa invades and degrades fly tissues and uses them as a nutrient source (224). A prior injection with nonpathogenic variants partially protects against a subsequent infection by $P$. aeruginosa, and this effect is Toll- and Imd-dependent. Mutants deficient for Toll and Imd pathways are more susceptible to $P$. aeruginosa than are wild-type flies $(224,225)$. This indicates that $P$. aeruginosa is somewhat sensitive to the fly humoral response, but can ultimately over- come it. A microarray analysis indicated that AMP gene expression is delayed when flies are challenged with a pathogenic strain of $P$. aeruginosa as compared to nonpathogenic bacteria (225). Altogether these data point to the existence of a complex set of strategies used by $P$. aeruginosa to suppress and escape the immune response.

Many $P$. aeruginosa mutants with decreased pathogenicity have been identified, but none of these mutations leads to a complete loss of virulence $(219,221,226)$. Toxins such as phenazine and pyoverdine, as well as injection of virulence factors into host cells through the Type III secretion system, participate in virulence. A recent study indicates that $P$. aeruginosa suppresses its own phagocytosis by Drosophila hemocytes through the injection, via the Type III apparatus, of a Rho-GAP GTPase toxin that impairs hemocyte function $(227,228)$.

Two slow killers: Mycobacterium marinum and Salmonella typhimurium. $M y-$ cobacterium marinum, a pathogenic bacterium closely related to $M$. tuberculosis, causes a tuberculosis-like disease in fish and frogs. It is lethal to flies within 8 days following injection of a low dose (229). M. marinum initially proliferates inside plasmatocytes and spreads later in the course of infection to the whole organism. Intracellular M. marinum blocks vacuolar acidification, suggesting that it successfully subverts fly plasmatocytes as it does with vertebrate macrophages. Consistent with an intracellular localization of this bacterium, injection of $M$. marinum does not trigger AMP gene expression and as a consequence $i m d$ and Toll mutant flies do not exhibit higher susceptibility than wild-type flies. Flies infected with $M$. marinum progressively lose energy reserves, and this wasting-like process participates in the pathogenesis (229a).

Similarly, injection of Salmonella typhimurium causes death within 7-9 days. Bacterial growth in the hemolymph is limited by the Imd pathway (230). Like M. marinum, 
Ecc15: Erwinia carotovora 15 this bacterium survives in hemocytes and impairs their function, leading to slow death.

Although M. marinum and S. typhimurium are not true Drosophila pathogens, these studies suggest that one mechanism used by bacteria to resist the systemic immune response is to reside inside hemocytes and to alter their phagocytic function, similar to intracellular pathogens in vertebrates.

Drosophila as a model host to identify bacterial virulence factors. The good correlation between virulence factors of $P$. aeruginosa required to infect Drosophila and those required to infect vertebrates, as well as the observation that many human pathogenic bacteria have a broad host range including invertebrates, has launched the use of D. melanogaster and C. elegans as alternative model hosts $(219,231,232)$. Indeed, several studies suggest that Drosophila can be used to screen for virulence factors and to analyze the complex interactions between pathogenic bacteria and the innate host defense (219, 221-230, 233-234). Recently, high-throughput RNAi screens in S2 cells have been developed to systematically screen for host components required for bacterial internalization and spreading. Such large-scale screens have been applied to L. monocytogenes, Legionella pneumophila, and Mycobacterium fortuitum (176-179, 233, 234).

Even though the requirement for some virulence factors depends on a specific host, invertebrate models may now provide a powerful tool to reveal new aspects of bacterial pathogenesis.

Immunity after oral bacterial infection. Injuries are probably not a frequent source of entry of pathogens in Drosophila, unlike oral infection upon ingestion. One limitation of approaches using injection is that they bypass the initial steps of naturally occurring infections including bacterial colonization, persistence, and the host local immune response. In addition, the microorganisms generally used are not true pathogens of Drosophila. To overcome this limitation, the use of natural oral infections with infectious bacteria has been developed.

Flora and bacterial pathogens of Drosophila. Drosophila flies live on fermenting medium and as a consequence their gut flora will reflect bacteria living in their food (218). It is not clear whether a stable gut flora exists in this insect. The study of flies raised axenically (deprived of their normal flora) points to a contribution of this flora to the physiology of these insects (218). To date, the influence of this natural gut flora on the Drosophila immune system has not been investigated.

Fruit flies have been involved in the transmission of many phytopathogenic bacteria and probably participate in their dissemination in the environment (218). Recently, a few bacterial strains were found to be able to trigger an immune response in flies or to be pathogenic after oral infection. These include S. marcescens Db11, Erwinia carotovora 15 (Ecc15), and Pseudomonas entomophila. These bacteria can establish a persistent interaction with their host.

S. marcescens Db11. S. marcescens Db11 was isolated from moribund flies in the laboratory (222). Oral infection by $S$. marcescens kills flies within 4 to 8 days. This bacterium persists in the gut where it triggers local AMP gene expression and crosses the intestinal barrier to reach the hemocoel without, however, eliciting a systemic immune response (81). S. marcescens may not be detected by the fly immune system as a result of a low release of PGN into the hemolymph. Two host defense mechanisms contribute to host survival against $S$. marcescens: (a) local AMP expression in the gut and (b) phagocytosis of $S$. marcescens in the hemolymph (81, 171).

Erwinia carotovora 15 (Ecc15). A Gramnegative bacterial strain, $E c c 15$, was initially identified for its capacity to persist in the 
Drosophila gut and to trigger both local and systemic immune responses following oral infection $(82,154)$. Both responses are mediated by the Imd pathway. E. carotovora are phytopathogenic bacteria that cause soft rot in fruit and use insects as vectors. Ecc15 persists in the gut of larvae while not killing them. This effect is mediated by a single gene, $E r$ winia virulence factor (Evf) (235). Evf plays a direct role in gut persistence as its transfer into other Gram-negative bacteria enables them to persist in the Drosophila gut and to elicit a systemic immune response (236). Evf encodes a novel protein with no homology in the databases. The exact mechanism by which Evf promotes bacterial persistence in the gut is not known. That Evf is found only in a subset of $E$. carotovora strains that have infectious properties toward Drosophila suggests that it is an example of a gene that promotes survival and dissemination of bacteria in their environment.

P. entomophila. P. entomophila is a novel Pseudomonas species collected from a fly in Guadeloupe (237). In contrast to Ecc15, P. entomophila is highly pathogenic for Drosophila as well as for other insect species by destroying the gut. In addition, this bacterium induces a food-uptake blockage in Drosophila larvae. Although P. entomophila triggers both local and systemic activation of the Imd pathway, only the gut antimicrobial response contributes to host survival after oral infection (238). One mechanism used by $P$. entomophila to counteract the gut immune response is the secretion of an abundant protease, AprA, that degrades AMPs produced by gut epithelia and thereby promotes bacterial persistence (238). S. marcescens also expresses a protease (222). Taken together, these results suggest that proteases may represent a common strategy used by pathogens to circumvent the local antimicrobial host defense of insects (Figure 5). Many pseudomonads and other bacteria express proteases similar to AprA but are not able to infect Drosophila by oral ingestion. This indicates that $P$. entomophila virulence is multifactorial, AprA being one virulence factor among others. The complete sequencing of the P. entomophila genome has revealed the existence of large sets of genes encoding putative virulence factors such as proteases, lipases, toxins, and proteins involved in alginate synthesis (239).

Gut infection and fat body immune response. Both Ecc15 and P. entomophila can trigger a strong systemic immune response in Drosophila after oral infection, pointing to the existence of a signaling mechanism from the gut to the fat body. This immune response correlates with the capacity of these bacterial species to persist and multiply inside the gut and does not appear to rely on physical crossing of the gut wall $(236,237)$. It has been proposed that this systemic immune response is mediated by the translocation of small PGN fragments from the gut lumen to the hemolymph (116). This view is supported by the observation that ingestion of monomeric PGN can stimulate a strong systemic immune response in PGRP-LB RNAi flies that have reduced amidase activity and are unable to degrade PGN to its nonimmunogenic form. Transfer of PGN would provide an indirect mechanism for recognition of Gram-negative bacteria that may explain the existence of different PGRP-LC isoforms devoted to the detection of monomeric PGN. Alternatively, one study points to a key role of nitric oxide as a signaling molecule, in that ingestion of nitric oxide is sufficient to trigger an immune response in the absence of an infection $(240,241)$.

Finally, a role for hemocytes in the signaling between gut infection and fat body has been proposed based on the observation that domino larvae lacking hemocytes failed to activate a systemic immune response after Ecc15 infection (154). Cells that express hemocyte markers are embedded in the first loop of the midgut (B. Lemaitre, unpublished data). These Drosophila hemocytes might act similarly to vertebrate M-cells that have an immune function in the vertebrate digestive 
tract by sampling the contents of the gut lumen.

Natural bacterial infection: concluding remarks. The use of naturally infectious bacteria has revealed the important contribution of the local immune defense $(81,158,238)$. From this point of view, note that local AMP synthesis in epithelia is a conserved defense mechanism within the animal kingdom, whereas systemic AMP production by the fat body is probably a more recent adaptation because it appears to be specific to holometabolous insects. Natural infection studies also reveal common strategies used by bacteria to subvert the insect immune system such as the production of proteases. Why a given bacterial species can trigger an immune response upon ingestion is not yet understood. This could be a simple consequence of bacterial persistence in a compartment of the gut (leading to a local increase of a bacterial elicitor) or could reflect specific properties of the bacteria (release of PGN). Furthermore, P. entomophila infection triggers a systemic immune response that has no overt function against bacteria remaining in the gut lumen.

Bacterial endosymbionts: Wolbachia. In contrast to other insect groups, heritable symbionts are uncommon in Drosophila species, possibly reflecting a robust innate immune response that eliminates many bacteria (218). The most frequent endosymbionts are $\mathrm{Wol}_{\text {- }}$ bachia, which are intracellular bacteria present in $30 \%$ of all laboratory stocks as well as in populations in the wild. Wolbachia parasites, which can only be transmitted vertically from a female host to her offspring, have evolved strategies for maximizing their transmission, such as changing the sex of male fly embryos. They colonize many different tissues but have a specific tropism to reproductive tissues to ensure their transmission. The recent discovery of PGRP-LE as an intracellular sensor of Gram-negative bacteria opens the possibilities of an immune defense to intracellular bacteria such as Wolbachia (127).

\section{Immunity to Fungi}

Extensive ecological studies have been performed on the association between flies and yeasts. In the wild, flies also play a role in the dissemination of phytopathogenic fungi. To date, the fly immune response has been analyzed in detail in response to two fungi: Beauveria bassiana and Candida albicans.

B. bassiana. B. bassiana is an entomopathogenic fungus that infects many insect species by penetrating their cuticle. Conidia of B. bassiana germinate on the host cuticle and differentiate to form an appressorium. An infecting hypha penetrates through the host cuticle and eventually reaches the hemocoel. Studies on Metarbizium anisopliae, a fungus related to $B$. bassiana, have shown that entry into the host involves enzymatic degradation mediated by chitinases, lipases, and proteases such as PR1 (242). Natural infection of Drosophila by B. bassiana (initiated by applying fungal spores on the cuticle) leads to the expression of the antifungal peptide genes Drosomycin and Metchnikowin and other Toll-dependent immune genes through a selective activation of the Toll pathway (19, 83). Toll-deficient mutants show increased susceptibility to B. bassiana, which cannot be rescued by ectopic expression of Drosomycin (18). Thus, the mechanisms mediating Toll resistance against $B$. bassiana have yet to be established. Finally, melanization is also believed to play an important role in the insect host defense mechanism against fungi $(214,217)$.

Activation of the Toll pathway by fungi is mediated by GNBP3 via the sensing of $\beta(1,3)$ glucan. Curiously, even GNBP3 mutant flies upregulate their Toll pathway when they become infected with B. bassiana (131c). In this condition, the Toll pathway is thought to be triggered by a fungal protease $\mathrm{PR} 1$, which can lead to cleavage of the host SP Persephone. In a second step, Persephone activates the SP cascade acting upstream of Toll. Thus, flies may sense infection by $B$. bassiana through 
the production of a fungal virulence factor required for entry.

C. albicans. C. albicans is an opportunistic human pathogen. It is a dimorphic fungus, and it has been suggested that the yeast-tohyphae transition plays a pivotal role in its virulence. Injection of $C$. albicans into wildtype flies induces moderate killing, but Tolldeficient mutants are highly sensitive to this fungus (243). C. albicans proliferates extensively as pseudohyphae, in a manner similar to that which occurs in a mammalian host model. Toll pathway activation by $C$. albicans requires GNBP3 (131c). In addition, C. albicans is rapidly phagocytosed by hemocytes, and experiments in S2 cells have shown that this process is enhanced by Mcr (178).

\section{Immunity to Parasitoid Wasps}

Parasitoids are insects, mostly wasps (Hymenoptera), that parasitize invertebrates, mainly insects (244). In contrast to parasites, they ultimately kill their hosts by the ravenous feeding of the preimaginal stages of the parasitoids. Depending on the species, females lay one or more eggs into their host. Upon completion of their development, adult parasitoids emerge, mate, and disperse in the environment in search of hosts to complete their life cycle (Figure $8 \boldsymbol{a}$ ). Of the approximately 50 known species of Drosopbila parasitoids, those belonging to the Leptopilina, Asobara, and Ganapsis genera have been studied most intensively. Environmental studies indicate that there is a high degree of parasitization of Drosophila populations by wasps (244). More recently, immunological aspects of Drosophila-parasitoid relationships have been analyzed. In Drosophila, cellular encapsulation is the most important component of the immune response against parasitoids (Figure $8 \boldsymbol{b}, \boldsymbol{c}$ ). D. melanogaster and Drosophila yakuba resistance to infestations of Leptopilina boulardi are both under the genetic control of one major gene $(245,245 a)$. For successful parasitism, parasitoids must circumvent the host immunity using passive and/or active mechanisms.

Immune local evasion. Immune local evasion is achieved when the parasitoid egg develops in a host site inaccessible to hemocytes or is embedded into host tissues. The egg can also use a type of molecular disguise that prevents hosts from recognizing it as nonself or can be covered by factors causing a local inactivation of the host defense. An example of local evasion is observed in Asobara tabida, a braconid wasp that parasitizes Drosophila larvae in Europe and North America $(246,247)$. Parasitization by $A$. tabida provokes a transient activation of the host immune system. However, eggs of $A$. tabida possess a sticky chorion permitting their attachment to host tissues. Attachment of the chorion leads to the complete embedding of the parasitoid egg within the host tissues, preventing hemocytes from agglutinating at the egg surface. Thus $A$. tabida eggs are initially recognized by the host, but there seems to be a race between the immune reaction and the parasitoid evasion mechanism to avoid encapsulation (248). The molecular basis of this evasion mechanism is not known.

Active immune suppression. The active suppression of the immune response generally involves substances that are introduced into the host by the female wasp at the time of oviposition. These mechanisms involve female products such as ovarian protein venoms, virus-like particles, or polydnaviruses. One of the best examples of active immune suppression is observed in the interaction between $D$. melanogaster and the parasitic wasps L. boulardi or L. beterotoma. Most strains of these wasp species are able to bypass the immune response of $D$. melanogaster. They suppress the fly encapsulation response notably by changing lamellocyte morphology from a discoidal to a bipolar shape, which presumably diminishes their ability to adhere and to form capsules (Figure 8d ) (249-251). 


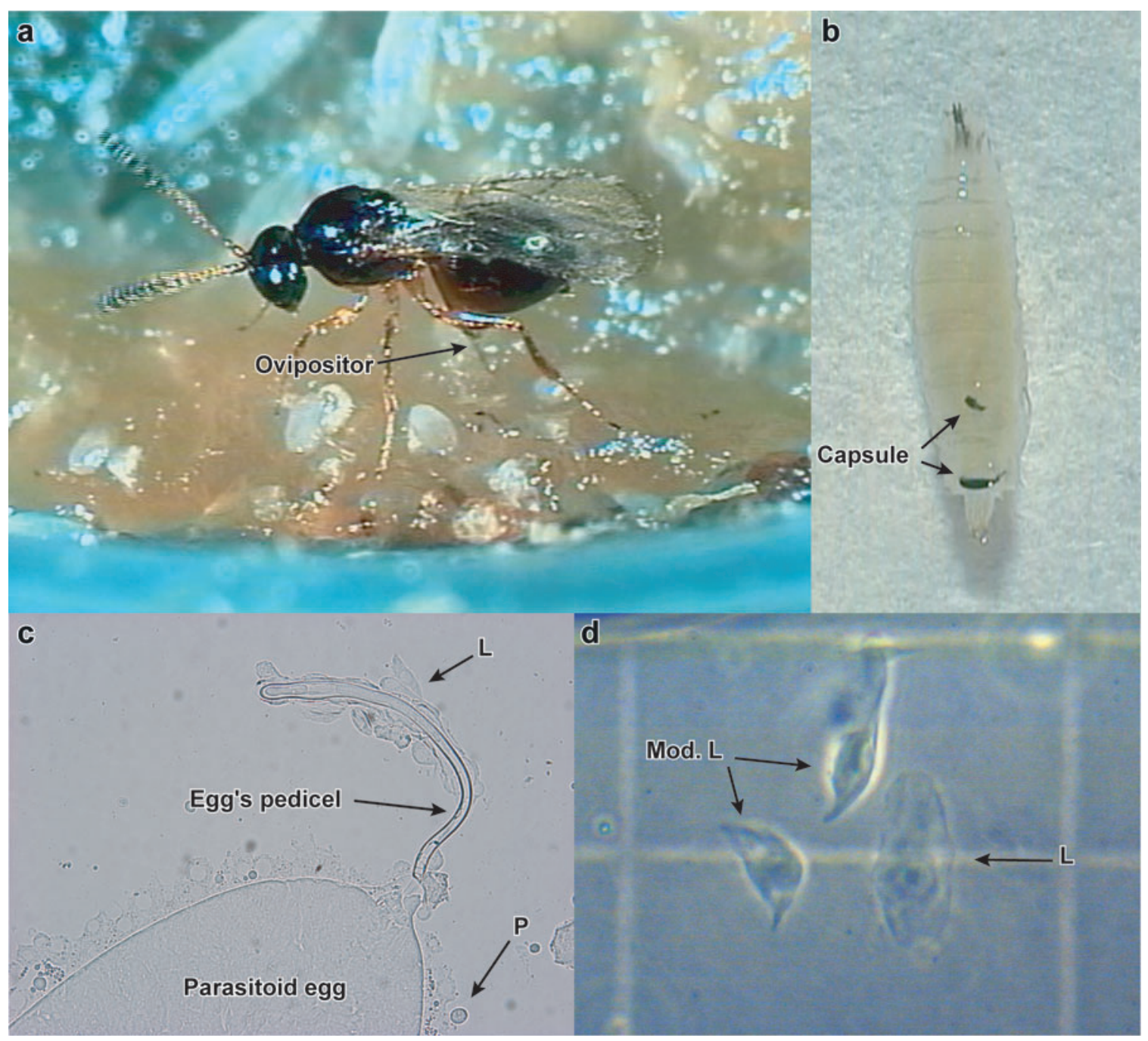

Figure 8

Drosophila infection by parasitoid wasp. (a) The parasitic wasp Leptopilina boulardi infects Drosopbila second instar larvae (L2) and deposits eggs within the body cavity. $(b, c)$ Encapsulation of the egg is the major host defense against parasitoid infection. The black capsules are visible through the larval cuticle (b). P, plasmatocyte. (d) L. boulardi can suppress the Drosophila encapsulation response by altering lamellocyte (L) morphology from a discoidal to a bipolar shape. L, normal lamellocyte; mod. L, bipolar-shaped lamellocyte. Courtesy of Aurore Dubuffet $(a-c)$ and Corinne Labrosse $(d)$, University of Tours, France.

Virus-like particles (VLPs) produced in the female long gland and the reservoir are injected together with the eggs and have been associated with immune suppression. $\mathrm{P} 4$, one of the proteins present in the long glands, was recently isolated from $L$. boulardi and demonstrated to be a Rho-GAP domain-containing protein $(252,253)$. Rho-GAP proteins are acting as inhibitors of Rho GTPases that are involved in the actin cytoskeleton reorganization. The observations that $(a)$ the ability to detect the $\mathrm{P} 4$ protein in female parasitoids correlates with their virulence and $(b)$ its injection in the host alters lamellocyte morphology 
establish this protein as a main immunesuppressive factor of L. boulardi. Similarly, a $40-\mathrm{kDa}$ protein with immune-suppressive properties was identified at the surface of VLPs in L. heterotoma $(254,255)$.

Another strategy of immune suppression is observed with Asobara citri, a parasitoid devoid of VLPs. A. citri appears to suppress the host immune system by directly affecting the hematopoietic organ and, consequently, the number of circulating hemocytes (256). Indeed, the size of the anterior lymph glands is strongly reduced in larvae of $D$. melanogaster parasitized by $A$. citri. The molecular mechanism underlying lymph gland necrosis caused by $A$. citri is not known.

\section{ANTIVIRAL IMMUNITY}

Viruses are important natural pathogens of D. melanogaster: $40 \%$ of all flies are infected with horizontally transmitted viruses, and vertical transmission of viruses is also common in this species $(218,257)$. More than 25 distinct Drosophila viruses have been identified, all RNA viruses $(218,257 \mathrm{a})$. Although there is an extensive literature on the association between viruses and Drosophila, only the immune response to viruses, especially to the Sigma and Drosophila C virus (DCV), has been investigated. Drosophila host reactions to viruses are clearly distinct from those involved in the defense against microbes or parasites. To date, RNAi is the sole immune effector mechanism directed against viruses identified in this insect.

\section{Sigma Virus}

The Sigma virus, a rhabdovirus related to vesicular stomatitis virus of horses, is widespread in natural populations of $D$. melanogaster and is normally transmitted vertically from fly to fly via the egg. Viruses can, however, also be artificially transmitted by injection of tissue extracts derived from an infected fly. Flies carrying the Sigma virus appear normal, but die after benign exposure to carbon dioxide. Natural populations of $D$. melanogaster are often polymorphic for nonpermissive alleles of genes that are known collectively as ref (refractory) and that prevent virus replication in cells. $\operatorname{Ref}(2) P$, the bestcharacterized among the five ref genes identified, encodes a PEST domain protein that is highly variable in sequence between alleles of natural populations $(258,259)$. A null mutation in $\operatorname{ref}(2) P$ is permissive to the Sigma virus, but causes male sterility, indicating that this gene has an endogenous function in flies. The molecular mechanism by which the restrictive allele of $\operatorname{ref}(2) P$ blocks Sigma replication is not known, although direct interaction has been suggested between $\operatorname{ref}(2) P$ protein encoded by restrictive alleles and the viral RNA polymerase (260). Because the Sigma virus can mutate to overcome the fly resistance to infection resulting from a refractory phenotype, there is probably an arms race between the viral genome and the host genome. Collectively, these studies indicate that a high polymorphism of ref genes plays an important role at the level of populations to limit Sigma infections.

\section{Drosophila C Virus (DCV)}

DCV is a nonenveloped single-stranded RNA virus similar to vertebrate picornaviruses. Flies isolated in different parts of the world display varying susceptibility to this virus. It is horizontally transmitted through contact or ingestion, but to date only injections have been used to ensure reproducible infection and lethality under laboratory conditions. Genome screening with S2 cells has identified a large number of Drosophila genes required for virus entry and replication, notably genes encoding components of the clathrin-mediated endocytic pathway (261-262a).

Proteomic and microarray analyses were performed on DCV-injected flies to analyze the global immune response to DCV. One molecule, pherokine-2, was found to be induced at the posttranscriptional level in the
DCV: Drosophila C virus 
hemolymph of DCV-infected flies (263). The high expression of pherokine-2 during metamorphosis pointed to a possible role of this gene in tissue remodeling. DCV infection triggers a transcriptional response in flies that significantly differs from that triggered by bacteria or fungi (91). Some of the DCVspecific responsive genes are regulated by the JAK-STAT pathway, a cascade that plays an important role in the antiviral response in mammals. One of the DCV-responsive genes, virl, is induced $24 \mathrm{~h}$ after viral infection in the ventral epidermis, but not in the fat body, in a JAK-STAT-dependent manner. A role for the JAK-STAT pathway in antiviral defense is also supported by the observation that flies deficient in the JAK kinase Hopscotch exhibit increased susceptibility to DCV and contain a higher viral load. These data suggest that flies produce antiviral molecules in a JAK-STAT-dependent manner, although, to date, none of the identified DCV-regulated genes has been shown to manifest direct antiviral activity. DCV infection does not induce expression of the JAK-STAT-dependent stress-induced gene Turandots, at least in the first 3 days of infection before tissue damage becomes apparent. Some components of the Toll pathway (Toll and Dif, but not Pelle and Tube) have also been implicated in the resistance against Drosopbila $\mathrm{X}$ virus (264).

These studies support the existence of an antiviral signaling response in Drosopbila and raise many new questions (265). For one, the mechanisms by which Drosophila recognizes viral infection have not yet been worked out. In particular, it will be important to determine whether the transcriptional response to viral infection is triggered by intracellular pattern recognition receptors and/or can depend on signals from virus-induced tissue damage. A second point of importance will be the identification of antiviral molecules in Drosophila. Finally, it seems appropriate to study the immune response after natural viral infection because the route of entry may influence the host response: Only few genes were induced in mi- croarray studies after oral ingestion of DCV (266), in contrast to the robust response observed after DCV injection (91).

\section{RNAi as an Antiviral Immune Response Against RNA Viruses}

RNAi provides an antiviral defense in plants and animals that is able to seek out and destroy viral RNA. RNAi is initiated by the recognition of dsRNA through Dicer 2, which cleaves newly synthesized viral dsRNA, generating siRNAs (small interfering RNA) that "guide" the RISC complex to specifically recognize and degrade viral RNA. Recent reports have underlined the importance of this mechanism in the Drosophila antiviral response. Mutations in argonaute-2 or Dicer 2, which affect the RNAi pathway, increased the susceptibility of flies to a large number of RNA viruses including DCV, Flock House virus (FHV), Sinbis, and Drosophila X virus (267-269a). Successful infection and killing of Drosophila by the insect nodavirus or FHV are strictly dependent on the viral protein B2, a potent inhibitor of dsRNA processing by Dicer. A significant role of RNAi in the Drosophila antiviral defense is further supported by the observation that three genes involved in the RNAi response against viruses, but not their housekeeping miRNA paralogs, are in the top $3 \%$ of fastevolving genes in the D. melanogaster genome, which is often a signature of a host-pathogen arms race (270).

Although still preliminary, these studies suggest the existence of two types of responses to virus infection: degradation of viral RNA by RNAi and cytokine activation through the JAK-STAT pathway of a number of genes, which may counter viral infection.

\section{PERSPECTIVES}

In recent years considerable progress has been made in our understanding of the immune response of Drosophila, now one of the best-characterized host defense systems of metazoans. The success of this model largely 
relies on the possibility of applying genetic and genomic approaches to this organism. This situation will probably prevail in the future because Drosophila genetics remain among the most powerful and cost-effective approaches when compared to other models. Indeed, injection of dsRNA, which opened the route to functional studies in other insects, has its limitations. In particular, the injection procedure can perturb the response under investigation, and this may be critical when analyzing subtle aspects of the immune system. Ultimately, classical genetics, including the generation of animals carrying multiple mutations in defined genetic backgrounds, are feasible in Drosophila, but not in other insects. Such methodology thus remains mandatory to the generation and validation of solid data.

An attractive feature of the fly immune response is the existence of multiple defense "modules" that can be deployed in a coordinated response against distinct pathogens. The prominent immune reactions, such as AMP production, iron sequestration, phagocytosis, and ROS production, appear to be shared with vertebrates, whereas others, such as melanization and encapsulation by lamellocytes, are restricted to invertebrates. Analyzing the precise molecular mechanisms underlying each of these reactions remains an essential task for our full understanding of the fly immune response. In parallel, investigations concentrating on the global immune response to one specific pathogen are complementary since they provide a more integrated view of the immune system demonstrating how these defense "modules" interact. The hope is that these combined approaches will reveal more coherence among the many aspects of fly defense mechanisms, which still appear dissociated. In the future, addressing the interactions between immunity and other physiological functions (e.g., metabolism, or adaptation to environmental stress) will assist in discerning the relationships of the immune system with other aspects of fly life.
The remarkable similarities between Drosophila host defense and essential facets of vertebrate innate immunity clearly point to a common ancestry in evolution. This is particularly striking with regard to the intracellular signaling pathways activated upon infections. A precise understanding of the evolution of innate immune responses in metazoans will obviously require the study of these defense reactions in other invertebrate species and should allow discrimination between recent acquisitions and conserved mechanisms. From this point of view, the recent genomic sequencing of several Drosophila species as well as that of other insects has also launched Drosophila as a model for studying microevolution between closely related species. Several interesting studies, not discussed in this review, are investigating the genetic basis of immune competence variations among Drosophila populations and the diversity of immune genes among insect species. Major differences can be observed between closely related species. To illustrate this, some Drosophila species, such as D. pseudoobscura, lack the capacity to encapsulate parasitoids due to the absence of lamellocytes (183). It has been proposed that this natural case of constitutive immune deficiency could represent an unexpected and risky strategy: The absence of a particular immune "module" may be beneficial as it economizes valuable resources allocated to this mechanism. Thus, studies comparing immune systems of related species or even populations of $D$. melanogaster may reveal differences in host defense strategies. This comparison will probably underline the importance of ecology in shaping an immune system and should lead to a better understanding of adaptation. As Jiggins \& Kim point out (271), there is no reported specialist fungal or bacterial pathogen for D. melanogaster. This may be related to its ecology as Drosophila have short life spans and live on ephemeral food patches. It is possible that most $D$. melanogaster pathogens are generalists infecting many species, which in 
turn restricts the opportunity for coevolution. This mode of life has strong implications for determining the nature of the immune system. Future studies may well reveal interesting links between Drosophila immune defense and the ecology of this insect.

\section{ACKNOWLEDGMENTS}

The authors apologize for their inability to quote many additional contributions due to space limitations. We thank Charles Hetru for graphics conception; Christoph Scherfer, Marie Meister, Anna Zaidman, and Marylène Poirié for critical reading; and Ulrich Theopold, Corinne Labrosse, and Aurore Dubuffet for providing images.

\section{LITERATURE CITED}

1. Tzou P, De Gregorio E, Lemaitre B. 2002. How Drosophila combats microbial infection: a model to study innate immunity and host-pathogen interactions. Curr. Opin. Microbiol. 5:102-10

2. Hultmark D. 2003. Drosophila immunity: paths and patterns. Curr. Opin. Immunol. 15:1219

3. Hoffmann JA. 2003. The immune response of Drosophila. Nature 426:33-38

4. Brennan CA, Anderson KV. 2004. Drosophila: the genetics of innate immune recognition and response. Annu. Rev. Immunol. 22:457-83

5. Lemaitre B. 2004. The road to Toll. Nat. Rev. Immunol. 4:521-27

6. Rubin GM, Yandell MD, Wortman JR, Gabor Miklos GL, Nelson CR, et al. 2000. Comparative genomics of the eukaryotes. Science 287:2204-15

7. Boman HG, Nilsson I, Rasmuson B. 1972. Inducible antibacterial defense system in Drosophila. Nature 237:232-35

8. Imler JL, Bulet P. 2005. Antimicrobial peptides in Drosophila: structures, activities and gene regulation. Chem. Immunol. Allergy 86:1-21

9. Wicker C, Reichhart JM, Hoffmann D, Hultmark D, Samakovlis C, Hoffmann JA. 1990. Insect immunity: characterization of a Drosophila cDNA encoding a novel member of the diptericin family of immune peptides. F. Biol. Chem. 265:22493-98

10. Asling B, Dushay MS, Hultmark D. 1995. Identification of early genes in the Drosophila immune response by PCR-based differential display: the Attacin A gene and the evolution of attacin-like proteins. Insect. Biochem. Mol. Biol. 25:511-18

11. Bulet P, Dimarcq JL, Hetru C, Lagueux M, Charlet M, et al. 1993. A novel inducible antibacterial peptide of Drosophila carries an O-glycosylated substitution. F. Biol. Chem. 268:14893-97

12. Dimarcq JL, Hoffmann D, Meister M, Bulet P, Lanot R, et al. 1994. Characterization and transcriptional profiles of a Drosophila gene encoding an insect defensin. A study in insect immunity. Eur. F. Biochem. 221:201-9

13. Fehlbaum P, Bulet P, Michaut L, Lagueux M, Broeckaert W, et al. 1994. Insect immunity: Septic injury of Drosophila induces the synthesis of a potent antifungal peptide with sequence homology to plant antifungal peptides. F. Biol. Chem. 269:33159-63

14. Levashina E, Ohresser S, Bulet P, Reichhart J, Hetru C, Hoffmann J. 1995. Metchnikowin, a novel immune-inducible proline-rich peptide from Drosophila with antibacterial and antifungal properties. Eur. F. Biochem. 233:694-700

15. Kylsten P, Samakovlis C, Hultmark D. 1990. The cecropin locus in Drosophila: a compact gene cluster involved in the response to infection. EMBO F. 9:217-24 
16. Ekengren S, Hultmark D. 1999. Drosophila cecropin as an antifungal agent. Insect. Biochem. Mol. Biol. 29:965-72

17. Uttenweiler-Joseph S, Moniatte M, Lagueux M, Van Dorsselaer A, Hoffmann JA, Bulet P. 1998. Differential display of peptides induced during the immune response of Drosophila: a matrix-assisted laser desorption ionization time-of-flight mass spectrometry study. Proc. Natl. Acad. Sci. USA 95:11342-47

18. Tzou P, Reichhart JM, Lemaitre B. 2002. Constitutive expression of a single antimicrobial peptide can restore wild-type resistance to infection in immuno-deficient Drosophila mutants. Proc. Natl. Acad. Sci. USA 99:2152-57

19. De Gregorio E, Spellman PT, Rubin GM, Lemaitre B. 2001. Genome-wide analysis of the Drosophila immune response by using oligonucleotide microarrays. Proc. Natl. Acad. Sci. USA 98:12590-95

20. Irving P, Troxler L, Heuer TS, Belvin M, Kopczynski C, et al. 2001. A genome-wide analysis of immune responses in Drosophila. Proc. Natl. Acad. Sci. USA 98:15119-24

21. Boutros M, Agaisse H, Perrimon N. 2002. Sequential activation of signaling pathways during innate immune responses in Drosophila. Dev. Cell 3:711-22

22. Vierstraete E, Cerstiaens A, Baggerman G, Van den Bergh G, De Loof A, Schoofs L. 2003. Proteomics in Drosophila melanogaster: first 2D database of larval hemolymph proteins. Biochem. Biophys. Res. Commun. 304:831-38

23. Vierstraete E, Verleyen P, Baggerman G, D'Hertog W, Van den Bergh G, et al. 2004. A proteomic approach for the analysis of instantly released wound and immune proteins in Drosophila melanogaster hemolymph. Proc. Natl. Acad. Sci. USA 101:470-75

24. Levy F, Bulet P, Ehret-Sabatier L. 2004. Proteomic analysis of the systemic immune response of Drosophila. Mol. Cell. Proteomics 3:156-66

25. Levy F, Rabel D, Charlet M, Bulet P, Hoffmann JA, Ehret-Sabatier L. 2004. Peptidomic and proteomic analyses of the systemic immune response of Drosophila. Biochimie 86:60716

26. Ekengren S, Tryselius Y, Dushay MS, Liu G, Steiner H, Hultmark D. 2001. A humoral stress response in Drosophila. Curr. Biol. 11:714-18

27. Ekengren S, Hultmark D. 2001. A family of Turandot-related genes in the humoral stress response of Drosophila. Biochem. Biophys. Res. Commun. 284:998-1003

28. Yoshiga T, Georgieva T, Dunkov BC, Harizanova N, Ralchev K, Law JH. 1999. Drosophila melanogaster transferrin. Cloning, deduced protein sequence, expression during the life cycle, gene localization and up-regulation on bacterial infection. Eur. $\mathcal{F}$. Biochem. 260:414-20

29. Kadalayil L, Petersen UM, Engstrom Y. 1997. Adjacent GATA and kB-like motifs regulate the expression of a Drosophila immune gene. Nucleic Acids Res. 25:1233-39

30. Petersen UM, Kadalayil L, Rehorn KP, Hoshizaki DK, Reuter R, Engstrom Y. 1999. Serpent regulates Drosophila immunity genes in the larval fat body through an essential GATA motif. EMBO F. 18:4013-22

31. Tingvall TO, Roos E, Engstrom Y. 2001. The GATA factor Serpent is required for the onset of the humoral immune response in Drosophila embryos. Proc. Natl. Acad. Sci. USA 98:3884-88

32. Uvell H, Engstrom Y. 2003. Functional characterization of a novel promoter element required for an innate immune response in Drosophila. Mol. Cell. Biol. 23:8272-81

33. Senger K, Armstrong GW, Rowell WJ, Kwan JM, Markstein M, Levine M. 2004. Immunity regulatory DNAs share common organizational features in Drosophila. Mol. Cell 13:19-32 
34. Kappler C, Meister M, Lagueux M, Gateff E, Hoffmann JA, Reichhart JM. 1993. Insect immunity. Two $17 \mathrm{bp}$ repeats nesting a $\mathrm{kB}$-related sequence confer inducibility to the diptericin gene and bind a polypeptide in bacteria-challenged Drosophila. EMBO $\mathrm{F}$. 12:1561-68

35. Engstrom Y, Kadalayil L, Sun SC, Samakovlis C, Hultmark D, Faye I. 1993. kB-like motifs regulate the induction of immune genes in Drosophila. F. Mol. Biol. 232:327-33

36. Meister M, Braun A, Kappler C, Reichhart JM, Hoffmann JA. 1994. Insect immunity. A transgenic analysis in Drosophila defines several functional domains in the diptericin promoter. EMBO 7. 13:5958-66

37. Ip YT, Reach M, Engstrom Y, Kadalayil L, Cai H, et al. 1993. Dif, a dorsal-related gene that mediates an immune response in Drosophila. Cell 75:753-63

38. Reichhart JM, Georgel P, Meister M, Lemaitre B, Kappler C, Hoffmann JA. 1993. Expression and nuclear translocation of the rel/NF-kB-related morphogen dorsal during the immune response of Drosophila. C.R. Acad. Sci. III 316:1218-24

39. Dushay MS, Asling B, Hultmark D. 1996. Origins of immunity: Relish, a compound Rellike gene in the antibacterial defense of Drosophila. Proc. Natl. Acad. Sci. USA 93:10343-47

39a. Steward R. 1987. Dorsal, an embryonic polarity gene in Drosophila, is homologous to the vertebrate proto-oncogene -rel. Science 238:692-94

40. Petersen UM, Bjorklund G, Ip YT, Engstrom Y. 1995. The dorsal related immunity factor, Dif, is a sequence specific trans-activator of Drosophila cecropin gene expression. EMBO 7. 14:3146-58

41. Gross I, Georgel P, Kappler C, Reichhart JM, Hoffmann JA. 1996. Drosophila immunity: a comparative analysis of the Rel proteins dorsal and Dif in the induction of the genes encoding diptericin and cecropin. Nucleic Acids Res. 24:1238-45

42. Belvin MP, Anderson KV. 1996. A conserved signaling pathway: the Drosophila Tolldorsal pathway. Annu. Rev. Cell Dev. Biol. 12:393-416

43. Tauszig-Delamasure S, Bilak H, Capovilla M, Hoffmann JA, Imler JL. 2002. Drosophila MyD88 is required for the response to fungal and Gram-positive bacterial infections. Nat. Immunol. 3:91-97

44. Lemaitre B, Nicolas E, Michaut L, Reichhart JM, Hoffmann JA. 1996. The dorsoventral regulatory gene cassette Spätzle/Toll/cactus controls the potent antifungal response in Drosophila adults. Cell 86:973-83

44a. Rutschmann S, Kilinc A, Ferrandon D. 2002. Cutting edge: The Toll pathway is required for resistance to gram-positive bacterial infections in Drosophila. F. Immunol. 168:154246

45. Meng X, Khanuja BS, Ip YT. 1999. Toll receptor-mediated Drosophila immune response requires Dif, an NF-kB factor. Genes Dev. 13:792-97

46. Manfruelli P, Reichhart JM, Steward R, Hoffmann JA, Lemaitre B. 1999. A mosaic analysis in Drosophila fat body cells of the control of antimicrobial peptide genes by the Rel proteins Dorsal and DIF. EMBO 7. 18:3380-91

47. Rutschmann S, Jung AC, Hetru C, Reichhart JM, Hoffmann JA, Ferrandon D. 2000. The Rel protein DIF mediates the antifungal but not the antibacterial host defense in Drosophila. Immunity 12:569-80

48. Bettencourt R, Asha H, Dearolf C, Ip YT. 2004. Hemolymph-dependent and -independent responses in Drosophila immune tissue. F. Cell. Biochem. 92:849-63

49. De Gregorio E, Spellman PT, Tzou P, Rubin GM, Lemaitre B. 2002. The Toll and Imd pathways are the major regulators of the immune response in Drosophila. EMBO 7 . 21:2568-79 
50. Nicolas E, Reichhart JM, Hoffmann JA, Lemaitre B. 1998. In vivo regulation of the IKB homologue cactus during the immune response of Drosophila. 7. Biol. Chem. 273:1046369

51. Weber AN, Tauszig-Delamasure S, Hoffmann JA, Lelievre E, Gascan H, et al. 2003. Binding of the Drosophila cytokine Spätzle to Toll is direct and establishes signaling. Nat. Immunol. 4:794-800

52. Hu X, Yagi Y, Tanji T, Zhou S, Ip Y'T. 2004. Multimerization and interaction of Toll and Spätzle in Drosophila. Proc. Natl. Acad. Sci. USA 101:9369-74

53. Tauszig S, Jouanguy E, Hoffmann JA, Imler JL. 2000. Toll-related receptors and the control of antimicrobial peptide expression in Drosophila. Proc. Natl. Acad. Sci. USA 97:10520-25

54. Ooi JY, Yagi Y, Hu X, Ip YT. 2002. The Drosophila Toll-9 activates a constitutive antimicrobial defense. EMBO Rep. 3:82-87

55. Lemaitre B, Kromer-Metzger E, Michaut L, Nicolas E, Meister M, et al. 1995. A recessive mutation, immune deficiency (imd), defines two distinct control pathways in the Drosophila host defense. Proc. Natl. Acad. Sci. USA 92:9365-469

56. Corbo JC, Levine M. 1996. Characterization of an immunodeficiency mutant in Drosophila. Mech. Dev. 55:211-20

57. Levashina E, Ohresser S, Lemaitre B, Imler J. 1998. Two distinct pathways can control expression of the Drosophila antimicrobial peptide metchnikowin. F. Mol. Biol. 278:51527

58. Georgel P, Naitza S, Kappler C, Ferrandon D, Zachary D, et al. 2001. Drosophila immune deficiency (IMD) is a death domain protein that activates antibacterial defense and can promote apoptosis. Dev. Cell 1:503-14

59. Gottar M, Gobert V, Michel T, Belvin M, Duyk G, et al. 2002. The Drosophila immune response against Gram-negative bacteria is mediated by a peptidoglycan recognition protein. Nature 416:640-44

60. Choe KM, Werner T, Stoven S, Hultmark D, Anderson KV. 2002. Requirement for a peptidoglycan recognition protein (PGRP) in Relish activation and antibacterial immune responses in Drosophila. Science 296:359-62

61. Ramet M, Manfruelli P, Pearson A, Mathey-Prevot B, Ezekowitz RA. 2002. Functional genomic analysis of phagocytosis and identification of a Drosophila receptor for E. coli. Nature 416:644-48

62. Vidal S, Khush RS, Leulier F, Tzou P, Nakamura M, Lemaitre B. 2001. Mutations in the Drosophila dTAK1 gene reveal a conserved function for MAPKKKs in the control of rel/NF-kB-dependent innate immune responses. Genes Dev. 15:1900-12

63. Silverman N, Zhou R, Erlich RL, Hunter M, Bernstein E, et al. 2003. Immune activation of NF-KB and JNK requires Drosophila TAK1. F. Biol. Chem. 278:48928-34

64. Gesellchen V, Kuttenkeuler D, Steckel M, Pelte N, Boutros M. 2005. An RNA interference screen identifies Inhibitor of Apoptosis Protein 2 as a regulator of innate immune signaling in Drosophila. EMBO Rep. 6:979-84

65. Kleino A, Valanne S, Ulvila J, Kallio J, Myllymaki H, et al. 2005. Inhibitor of apoptosis 2 and TAK1-binding protein are components of the Drosophila Imd pathway. EMBO 7 . 24:3423-34

66. Zhuang ZH, Sun L, Kong L, Hu JH, Yu MC, et al. 2006. Drosophila TAB2 is required for the immune activation of JNK and NF-кB. Cell. Signal. 18:964-70

67. Leulier F, Lhocine N, Lemaitre B, Meier P. 2006. The Drosophila IAP DIAP2 functions in innate immunity and is essential to resist gram-negative bacterial infection. Mol. Cell. Biol. 26:7821-31 
68. Silverman N, Zhou R, Stoven S, Pandey N, Hultmark D, Maniatis T. 2000. A Drosophila IкB kinase complex required for Relish cleavage and antibacterial immunity. Genes Dev. 14:2461-71

69. Rutschmann S, Jung AC, Zhou R, Silverman N, Hoffmann JA, Ferrandon D. 2000. Role of Drosophila IKK $\gamma$ in a Toll-independent antibacterial immune response. Nature Immunol. 1:342-47

70. Lu Y, Wu LP, Anderson KV. 2001. The antibacterial arm of the Drosophila innate immune response requires an IkB kinase. Genes Dev. 15:104-10

71. Leulier F, Vidal S, Saigo K, Ueda R, Lemaitre B. 2002. Inducible expression of doublestranded RNA reveals a role for dFADD in the regulation of the antibacterial response in Drosophila adults. Curr. Biol. 12:996-1000

72. Naitza S, Rosse C, Kappler C, Georgel P, Belvin M, et al. 2002. The Drosophila immune defense against gram-negative infection requires the death protein dFADD. Immunity 17:575-81

73. Leulier F, Rodriguez A, Khush RS, Abrams JM, Lemaitre B. 2000. The Drosophila caspase Dredd is required to resist gram-negative bacterial infection. EMBO Rep. 1:353-58

74. Hedengren M, Asling B, Dushay MS, Ando I, Ekengren S, et al. 1999. Relish, a central factor in the control of humoral but not cellular immunity in Drosophila. Mol. Cell 4:82737

75. Khush RS, Cornwell WD, Uram JN, Lemaitre B. 2002. A ubiquitin-proteasome pathway represses the Drosophila immune deficiency signaling cascade. Curr. Biol. 12:1728-37

76. Cha GH, Cho KS, Lee JH, Kim M, Kim E, et al. 2003. Discrete functions of TRAF1 and TRAF2 in Drosophila melanogaster mediated by c-Jun N-terminal kinase and NFkB-dependent signaling pathways. Mol. Cell. Biol. 23:7982-91

77. Foley E, O'Farrell PH. 2004. Functional dissection of an innate immune response by a genome-wide RNAi screen. PLoS Biol. 2:e203

78. Zhou R, Silverman N, Hong M, Liao DS, Chung Y, et al. 2005. The role of ubiquitination in Drosophila innate immunity. F. Biol. Chem. 280:34048-55

79. Yagi Y, Ip YT. 2005. Helicase89B is a Mot1p/BTAF1 homologue that mediates an antimicrobial response in Drosophila. EMBO Rep. 6:1088-94

80. Tsuda M, Langmann C, Harden N, Aigaki T. 2005. The RING-finger scaffold protein plenty of SH3s targets TAK1 to control immunity signaling in Drosophila. EMBO Rep. 6:1082-87

80a. Kim M, Lee JH, Lee SY, Kim E, Chung J. 2006. Caspar, a suppressor of antibacterial immunity in Drosophila. Proc. Natl. Acad. Sci. USA 103:16358-63

81. Bangham J, Jiggins F, Lemaitre B. 2006. Insect immunity: the postgenomic era. Immunity 25:1-5

82. Tzou P, Ohresser S, Ferrandon D, Capovilla M, Reichhart JM, et al. 2000. Tissuespecific inducible expression of antimicrobial peptide genes in Drosophila surface epithelia. Immunity 13:737-48

83. Lemaitre B, Reichhart J, Hoffmann J. 1997. Drosophila host defense: differential induction of antimicrobial peptide genes after infection by various classes of microorganisms. Proc. Natl. Acad. Sci. USA 94:14614-19

84. Meister M, Richards G. 1996. Ecdysone and insect immunity: the maturation of the inducibility of the diptericin gene in Drosophila larvae. Insect. Biochem. Mol. Biol. 26:15560

85. Ligoxygakis P, Bulet P, Reichhart JM. 2002. Critical evaluation of the role of the Tolllike receptor 18-Wheeler in the host defense of Drosophila. EMBO Rep. 3:666-73 
86. Agaisse H, Perrimon N. 2004. The roles of JAK/STAT signaling in Drosophila immune responses. Immunol. Rev. 198:72-82

87. Barillas-Mury C, Han YS, Seeley D, Kafatos FC. 1999. Anopheles gambiae Ag-STAT, a new insect member of the STAT family, is activated in response to bacterial infection. EMBO 7. 18:959-67

88. Lagueux M, Perrodou E, Levashina EA, Capovilla M, Hoffmann JA. 2000. Constitutive expression of a complement-like protein in Toll and JAK gain-of-function mutants of Drosophila. Proc. Natl. Acad. Sci. USA 97:11427-32

89. Agaisse H, Petersen UM, Boutros M, Mathey-Prevot B, Perrimon N. 2003. Signaling role of hemocytes in Drosophila JAK/STAT-dependent response to septic injury. Dev. Cell 5:441-50

90. Brun S, Vidal S, Spellman P, Takahashi K, Tricoire H, Lemaitre B. 2006. The MAPKKK Mekk1 regulates the expression of Turandot stress genes in response to septic injury in Drosophila. Genes Cells 11:397-407

91. Dostert C, Jouanguy E, Irving P, Troxler L, Galiana-Arnoux D, et al. 2005. The JakSTAT signaling pathway is required but not sufficient for the antiviral response of Drosophila. Nat. Immunol. 6:946-53

92. Rämet M, Lanot R, Zachary D, Manfruelli P. 2001. JNK signaling pathway is required for efficient wound healing in Drosophila. Dev. Biol. 241:145-56

93. Galko MJ, Krasnow MA. 2004. Cellular and genetic analysis of wound healing in Drosophila larvae. PLoS Biol. 2:e239

94. Park JM, Brady H, Ruocco MG, Sun H, Williams D, et al. 2004. Targeting of TAK1 by the NF- $\mathrm{KB}$ protein Relish regulates the JNK-mediated immune response in Drosophila. Genes Dev. 18:584-94

95. Kim T, Yoon J, Cho H, Lee WB, Kim J, et al. 2005. Downregulation of lipopolysaccharide response in Drosophila by negative crosstalk between the AP1 and NF- $\mathrm{KB}$ signaling modules. Nat. Immunol. 6:211-18

96. Kallio J, Leinonen A, Ulvila J, Valanne S, Ezekowitz RA, Ramet M. 2005. Functional analysis of immune response genes in Drosophila identifies JNK pathway as a regulator of antimicrobial peptide gene expression in S2 cells. Microbes Infect. 7:811-19

97. Delaney JR, Stoven S, Uvell H, Anderson KV, Engstrom Y, Mlodzik M. 2006. Cooperative control of Drosophila immune responses by the JNK and NF- $\mathrm{BB}$ signaling pathways. EMBO 7. 25:3068-77

98. Asai T, Tena G, Plotnikova J, Willmann M, Chiu W, et al. 2002. MAP kinase signaling cascade in Arabidopsis innate immunity. Nature 415:977-83

99. Kim DH, Feinbaum R, Alloing G, Emerson FE, Garsin DA, et al. 2002. A conserved p38 MAP kinase pathway in Caenorbabditis elegans innate immunity. Science 297:977-83

100. Craig CR, Fink JL, Yagi Y, Ip YT, Cagan RL. 2004. A Drosophila p38 orthologue is required for environmental stress responses. EMBO Rep. 5:1058-63

101. Zhuang ZH, Zhou Y, Yu MC, Silverman N, Ge BX. 2005. Regulation of Drosophila p38 activation by specific MAP2 kinase and MAP3 kinase in response to different stimuli. Cell. Signal. 18:441-48

102. Igaki T, Kanda H, Yamamoto-Goto Y, Kanuka H, Kuranaga E, et al. 2002. Eiger, a TNF superfamily ligand that triggers the Drosophila JNK pathway. EMBO 7. 21:3009-18

103. Moreno E, Yan M, Basler K. 2002. Evolution of TNF signaling mechanisms: JNKdependent apoptosis triggered by Eiger, the Drosophila homolog of the TNF superfamily. Curr. Biol. 12:1263-68

104. Yoshida H, Kinoshita K, Ashida M. 1996. Purification of a peptidoglycan recognition protein from hemolymph of the silkworm, Bombyx mori. F. Biol. Chem. 271:13854-60 
105. Lee WJ, Lee JD, Kravchenko VV, Ulevitch RJ, Brey PT. 1996. Purification and molecular cloning of an inducible gram-negative bacteria-binding protein from the silkworm, Bombyx mori. Proc. Natl. Acad. Sci. USA 93:7888-93

106. Kang D, Liu G, Lundstrom A, Gelius E, Steiner H. 1998. A peptidoglycan recognition protein in innate immunity conserved from insects to humans. Proc. Natl. Acad. Sci. USA 95:10078-82

107. Mengin-Lecreulx D, Lemaitre B. 2005. Structure and metabolism of peptidoglycan and molecular requirements allowing its detection by the Drosophila innate immune system. 7. Endotoxin Res. 11:105-11

108. Leulier F, Parquet C, Pili-Floury S, Ryu JH, Caroff M, et al. 2003. The Drosophila immune system detects bacteria through specific peptidoglycan recognition. Nat. Immunol. 4:478-84

109. Kaneko T, Goldman WE, Mellroth P, Steiner H, Fukase K, et al. 2004. Monomeric and polymeric gram-negative peptidoglycan but not purified LPS stimulate the Drosophila IMD pathway. Immunity 20:637-49

110. Stenbak CR, Ryu JH, Leulier F, Pili-Floury S, Parquet C, et al. 2004. Peptidoglycan molecular requirements allowing detection by the Drosophila immune deficiency pathway. F. Immunol. 173:7339-48

111. Filipe SR, Tomasz A, Ligoxygakis P. 2005. Requirements of peptidoglycan structure that allow detection by the Drosophila Toll pathway. EMBO Rep. 6:327-33

112. Werner T, Liu G, Kang D, Ekengren S, Steiner H, Hultmark D. 2000. A family of peptidoglycan recognition proteins in the fruit fly Drosophila melanogaster. Proc. Natl. Acad. Sci. USA 97:13772-77

113. Steiner H. 2004. Peptidoglycan recognition proteins: on and off switches for innate immunity. Immunol. Rev. 198:83-96

114. Royet J, Reichhart JM, Hoffmann JA. 2005. Sensing and signaling during infection in Drosophila. Curr. Opin. Immunol. 17:11-17

115. Mellroth P, Karlsson J, Steiner H. 2003. A scavenger function for a Drosophila peptidoglycan recognition protein. 7. Biol. Chem. 278:7059-64

116. Zaidman-Remy A, Herve M, Poidevin M, Pili-Floury S, Kim MS, et al. 2006. The Drosophila amidase PGRP-LB modulates the immune response to bacterial infection. Immunity 24:463-73

116a. Mellroth P, Steiner H. 2006. PGRP-SB1: an N-acetylmuramoyl L-alanine amidase with antibacterial activity. Biochem. Biophys. Res. Commun. 350:994-99

117. BischoffV, Vignal C, Duvic B, Boneca IG, Hoffmann JA, Royet J. 2006. Downregulation of the Drosophila immune response by peptidoglycan-recognition proteins SC1 and SC2. PLoS Pathog. 2:e14

118. Kim MS, Byun M, Oh BH. 2003. Crystal structure of peptidoglycan recognition protein LB from Drosophila melanogaster. Nat. Immunol. 4:787-93

119. Chang CI, Pili-Floury S, Herve M, Parquet C, Chelliah Y, et al. 2004. A Drosophila pattern recognition receptor contains a peptidoglycan docking groove and unusual L,Dcarboxypeptidase activity. PLoS Biol. 2:e277

120. Lim JH, Kim MS, Kim HE, Yano T, Oshima Y, et al. 2006. Structural basis for preferential recognition of diaminopimelic acid-type peptidoglycan by a subset of peptidoglycan recognition proteins. F. Biol. Chem. 281:8286-95

121. Chang CI, Ihara K, Chelliah Y, Mengin-Lecreulx D, Wakatsuki S, Deisenhofer J. 2005. Structure of the ectodomain of Drosophila peptidoglycan-recognition protein LCa suggests a molecular mechanism for pattern recognition. Proc. Natl. Acad. Sci. USA 102:10279-84 
122. Chang CI, Chelliah Y, Borek D, Mengin-Lecreulx D, Deisenhofer J. 2006. Structure of tracheal cytotoxin in complex with a heterodimeric pattern-recognition receptor. Science 311:1761-64

123. Reiser JB, Teyton L, Wilson IA. 2004. Crystal structure of the Drosophila peptidoglycan recognition protein (PGRP)-SA at 1.56 ̊̊ resolution. F. Mol. Biol. 340:909-17

124. Mellroth P, Karlsson J, Hakansson J, Schultz N, Goldman WE, Steiner H. 2005. Ligand-induced dimerization of Drosophila peptidoglycan recognition proteins in vitro. Proc. Natl. Acad. Sci. USA 102:6455-60

125. Takehana A, Katsuyama T, Yano T, Oshima Y, Takada H, et al. 2002. Overexpression of a pattern-recognition receptor, peptidoglycan-recognition protein-LE, activates imd/relish-mediated antibacterial defense and the prophenoloxidase cascade in Drosophila larvae. Proc. Natl. Acad. Sci. USA 99:13705-10

126. Takehana A, Yano T, Mita S, Kotani A, Oshima Y, Kurata S. 2004. Peptidoglycan recognition protein (PGRP)-LE and PGRP-LC act synergistically in Drosophila immunity. EMBO 7. 23:4690-700

127. Kaneko T, Yano T, Aggarwal K, Lim JH, Ueda K, et al. 2006. PGRP-LC and PGRP-LE have essential yet distinct functions in the Drosophila immune response to monomeric DAP-type peptidoglycan. Nat. Immunol. 7:715-23

128. Michel T, Reichhart JM, Hoffmann JA, Royet J. 2001. Drosophila Toll is activated by Gram-positive bacteria through a circulating peptidoglycan recognition protein. Nature 414:756-59

129. Gobert V, Gottar M, Matskevich AA, Rutschmann S, Royet J, et al. 2003. Dual activation of the Drosophila Toll pathway by two pattern recognition receptors. Science 302:2126-30

130. Pili-Floury S, Leulier F, Takahashi K, Saigo K, Samain E, et al. 2004. In vivo RNAi analysis reveals an unexpected role for GNBP1 in the defense against Gram-positive bacterial infection in Drosophila adults. F. Biol. Chem. 279:12848-53

130a. Wang L, Weber AN, Atilano ML, Filipe SR, Gay NJ, Ligoxygakis P. 2006. Sensing of Gram-positive bacteria in Drosophila: GNBP1 is needed to process and present peptidoglycan to PGRP-SA. EMBO 7. 25:5005-14

131. Bischoff V, Vignal C, Boneca IG, Michel T, Hoffmann JA, Royet J. 2004. Function of the Drosophila pattern-recognition receptor PGRP-SD in the detection of Gram-positive bacteria. Nat. Immunol. 5:1175-80

131a. Kim YS, Ryu JH, Han SJ, Choi KH, Nam KB, et al. 2000. Gram-negative bacteriabinding protein, a pattern recognition receptor for lipopolysaccharide and $\beta$-1,3-glucan that mediates the signaling for the induction of innate immune genes in Drosophila melanogaster cells. F. Biol. Chem. 275:32721-72

131b. Ochiai M, Ashida M. 1988. Purification of a $\beta-1,3$-glucan recognition protein in the prophenoloxidase activating system from hemolymph of the silkworm, Bombyx mori. $\mathcal{F}$. Biol. Chem. 263:12056-62

131c. Gottar M, Gobert V, Matskevich A, Reichhart JM, Wang C, et al. 2006. Dual detection of fungal infections in Drosophila by recognition of glucans and sensing of virulence factors. Cell 127:1425-37

132. Krem MM, Cera ED. 2002. Evolution of enzyme cascades from embryonic development to blood coagulation. Trends Biochem. Sci. 27:67-74

133. Reichhart JM. 2005. Tip of another iceberg: Drosophila serpins. Trends Cell Biol. 15:659_ 65

134. Ross J, Jiang H, Kanost MR, Wang Y. 2003. Serine proteases and their homologs in the Drosophila melanogaster genome: an initial analysis of sequence conservation and phylogenetic relationships. Gene 304:117-31 
135. Lee KY, Zhang R, Kim MS, Park JW, Park HY, et al. 2002. A zymogen form of masquerade-like serine proteinase homologue is cleaved during prophenoloxidase activation by $\mathrm{Ca}^{2+}$ in coleopteran and Tenebrio molitor larvae. Eur. F. Biochem. 269:4375-83

136. Yu XQ, Jiang H, Wang Y, Kanost MR. 2003. Nonproteolytic serine proteinase homologs are involved in prophenoloxidase activation in the tobacco hornworm, Manduca sexta. Insect. Biochem. Mol. Biol. 33:197-208

137. Piao S, Song YL, Kim JH, Park SY, Park JW, et al. 2005. Crystal structure of a clipdomain serine protease and functional roles of the clip domains. EMBO 7. 24:4404-14

138. Kambris Z, Brun S, Jang IH, Nam HJ, Romeo Y, et al. 2006. Drosophila immunity: A large-scale in vivo RNAi screen identifies five serine proteases required for Toll activation. Curr. Biol. 16:808-13

139. Jang IH, Chosa N, Kim SH, Nam HJ, Lemaitre B, et al. 2006. A Spätzle-processing enzyme required for Toll signaling activation in Drosophila innate immunity. Dev. Cell $10: 45-55$

140. Ligoxygakis P, Pelte N, Hoffmann JA, Reichhart JM. 2002. Activation of Drosophila Toll during fungal infection by a blood serine protease. Science 297:114-16

141. Levashina EA, Langley E, Green C, Gubb D, Ashburner M, et al. 1999. Constitutive activation of Toll-mediated antifungal defense in serpin-deficient Drosophila. Science 285:1917-19

142. Lemaitre B, Meister M, Govind S, Georgel P, Steward R, et al. 1995. Functional analysis and regulation of nuclear import of dorsal during the immune response in Drosophila. EMBO 7. 14:536-45

143. Ligoxygakis P, Pelte N, Ji C, Leclerc V, Duvic B, et al. 2002. A serpin mutant links Toll activation to melanization in the host defense of Drosophila. EMBO 7. 21:6330-37

144. Scherfer C, Qazi MR, Takahashi K, Ueda R, Dushay MS, et al. 2006. The Toll immuneregulated Drosophila protein Fondue is involved in hemolymph clotting and puparium formation. Dev. Biol. 295:156-63

145. Mukae N, Yokoyama H, Yokokura T, Sakoyama Y, Nagata S. 2002. Activation of the innate immunity in Drosophila by endogenous chromosomal DNA that escaped apoptotic degradation. Genes Dev. 16:2662-71

146. Daffre S, Kylsten P, Samakovlis C, Hultmark D. 1994. The lysozyme locus in Drosophila melanogaster: an expanded gene family adapted for expression in the digestive tract. Mol. Gen. Genet. 242:152-62

147. Hultmark D. 1996. Insect lysozymes. EXS 75:87-102

148. Brey PT, Lee WJ, Yamakawa M, Koizumi Y, Perrot S, et al. 1993. Role of the integument in insect immunity: epicuticular abrasion and induction of cecropin synthesis in cuticular epithelial cells. Proc. Natl. Acad. Sci. USA 90:6275-79

149. Ferrandon D, Jung AC, Criqui M, Lemaitre B, Uttenweiler-Joseph S, et al. 1998. A drosomycin-GFP reporter transgene reveals a local immune response in Drosophila that is not dependent on the Toll pathway. EMBO f. 17:1217-27

150. Ryu JH, Nam KB, Oh CT, Nam HJ, Kim SH, et al. 2004. The homeobox gene Caudal regulates constitutive local expression of antimicrobial peptide genes in Drosophila epithelia. Mol. Cell. Biol. 24:172-85

151. Han SH, Ryu JH, Oh CT, Nam KB, Nam HJ, et al. 2004. The moleskin gene product is essential for Caudal-mediated constitutive antifungal Drosomycin gene expression in Drosophila epithelia. Insect. Mol. Biol. 13:323-27

152. Peng J, Zipperlen P, Kubli E. 2005. Drosophila sex peptide stimulates female innate immune system after mating via the Toll and Imd pathways. Curr. Biol. 15:1690-94 
153. Önfelt Tingvall T, Roos E, Engstrom Y. 2001. The imd gene is required for local Cecropin expression in Drosophila barrier epithelia. EMBO Rep. 2:239-43

154. Basset A, Khush RS, Braun A, Gardan L, Boccard F, et al. 2000. The phytopathogenic bacteria, Erwinia carotovora, infects Drosophila and activates an immune response. Proc. Natl. Acad. Sci. USA 97:3376-81

155. Ritsick DR, Edens WA, McCoy JW, Lambeth JD. 2004. The use of model systems to study biological functions of Nox/Duox enzymes. Biochem. Soc. Symp. 2004:85-96

156. Ha EM, Oh CT, Bae YS, Lee WJ. 2005. A direct role for dual oxidase in Drosophila gut immunity. Science 310:847-50

157. Ha EM, Oh CT, Ryu JH, Bae YS, Kang SW, et al. 2005. An antioxidant system required for host protection against gut infection in Drosophila. Dev. Cell 8:125-32

158. Ryu JH, Ha EM, Oh CT, Seol JH, Brey PT, et al. 2006. An essential complementary role of NF-KB pathway to microbicidal oxidants in Drosophila gut immunity. EMBO $\mathcal{F}$. 25:3693-701

159. Rizki TM. 1978. The circulatory system and associated cells and tissues. In The Genetics and Biology of Drosophila, ed. M Ashburner, TRF Wright, pp. 397-452. New York: Academic

160. Lanot R, Zachary D, Holder F, Meister M. 2000. Post-embryonic hematopoiesis in Drosophila. Dev. Biol. 230:243-57

161. Rizki T, Rizki R, Grell E. 1980. A mutant affecting the crystal cells in Drosophila melanogaster. Roux's Arch. Dev. Biol. 188:91-99

162. Tepass U, Fessler LI, Aziz A, Hartenstein V. 1994. Embryonic origin of hemocytes and their relationship to cell death in Drosophila. Development 120:1829-37

163. Holz A, Bossinger B, Strasser T, Janning W, Klapper R. 2003. The two origins of hemocytes in Drosophila. Development 130:4955-62

164. Evans CJ, Hartenstein V, Banerjee U. 2003. Thicker than blood: conserved mechanisms in Drosophila and vertebrate hematopoiesis. Dev. Cell 5:673-90

165. Meister M. 2004. Blood cells of Drosophila: cell lineages and role in host defense. Curr. Opin. Immunol. 16:10-15

166. Shresta R, Gateff E. 1982. Ultrastructure and cytochemistry of the cell-types in the tumorous hematopoietic organs and the hemolymph of the mutant lethal (1) malign blood neoplasm (l(1)mbn) of Drosophila melanogaster. Dev. Growth Differ. 24:83-98

167. Lebestky T, Jung SH, Banerjee U. 2003. A Serrate-expressing signaling center controls Drosophila hematopoiesis. Genes Dev. 17:348-53

168. Jung SH, Evans CJ, Uemura C, Banerjee U. 2005. The Drosophila lymph gland as a developmental model of hematopoiesis. Development 132:2521-33

169. Ramet M, Pearson A, Manfruelli P, Li X, Koziel H, et al. 2001. Drosophila scavenger receptor CI is a pattern recognition receptor for bacteria. Immunity 15:1027-38

170. Pearson A, Lux A, Krieger M. 1995. Expression cloning of dSR-CI, a class C macrophage-specific scavenger receptor from Drosophila melanogaster. Proc. Natl. Acad. Sci. USA 92:4056-60

171. Kocks C, Cho JH, Nehme N, Ulvila J, Pearson AM, et al. 2005. Eater, a transmembrane protein mediating phagocytosis of bacterial pathogens in Drosophila. Cell 123:335-46

172. Watson FL, Puttmann-Holgado R, Thomas F, Lamar DL, Hughes M, et al. 2005. Extensive diversity of Ig-superfamily proteins in the immune system of insects. Science 309:1874-78

173. Franc N, Dimarcq J, Lagueux M, Hoffmann J, Ezekowitz R. 1996. Croquemort, a novel Drosophila hemocyte/macrophage receptor that recognizes apoptotic cells. Immunity 4:431-43 
174. Garver LS, Wu J, Wu LP. 2006. The peptidoglycan recognition protein PGRP-SC1a is essential for Toll signaling and phagocytosis of Staphylococcus aureus in Drosophila. Proc. Natl. Acad. Sci. USA 103:660-65

175. Ju JS, Cho MH, Brade L, Kim JH, Park JW, et al. 2006. A novel 40-kDa protein containing six repeats of an epidermal growth factor-like domain functions as a pattern recognition protein for lipopolysaccharide. F. Immunol. 177:1838-45

176. Philips JA, Rubin EJ, Perrimon N. 2005. Drosophila RNAi screen reveals CD36 family member required for mycobacterial infection. Science 309:1251-53

177. Agaisse H, Burrack LS, Philips JA, Rubin EJ, Perrimon N, Higgins DE. 2005. Genomewide RNAi screen for host factors required for intracellular bacterial infection. Science 309:1248-51

178. Stroschein-Stevenson SL, Foley E, O'Farrell PH, Johnson AD. 2006. Identification of Drosophila gene products required for phagocytosis of Candida albicans. PLoS Biol. 4:e4

179. Benghezal M, Fauvarque MO, Tournebize R, Froquet R, Marchetti A, et al. 2006. Specific host genes required for the killing of Klebsiella bacteria by phagocytes. Cell. Microbiol. 8:139-48

180. Pearson AM, Baksa K, Ramet M, Protas M, McKee M, et al. 2003. Identification of cytoskeletal regulatory proteins required for efficient phagocytosis in Drosophila. Microbes Infect. 5:815-24

181. Seong CS, Varela-Ramirez A, Aguilera RJ. 2006. DNase II deficiency impairs innate immune function in Drosophila. Cell. Immunol. 240:5-13

182. Blandin S, Shiao SH, Moita LF, Janse CJ, Waters AP, et al. 2004. Complement-like protein TEP1 is a determinant of vectorial capacity in the malaria vector Anopheles gambiae. Cell 116:661-70

183. Eslin P, Doury G. 2006. The fly Drosophila subobscura: a natural case of innate immunity deficiency. Dev. Comp. Immunol. 30:977-83

184. Russo J, Dupas S, Frey F, Carton Y, Brehelin M. 1996. Insect immunity: early events in the encapsulation process of parasitoid (Leptopilina boulardi) eggs in resistant and susceptible strains of Drosophila. Parasitology 112:135-42

185. Nappi AJ, Vass E, Frey F, Carton Y. 1995. Superoxide anion generation in Drosophila during melanotic encapsulation of parasites. Eur. 7. Cell Biol. 68:450-56

186. Irving P, Ubeda JM, Doucet D, Troxler L, Lagueux M, et al. 2005. New insights into Drosophila larval haemocyte functions through genome-wide analysis. Cell. Microbiol. 7:335-50

187. Lavine MD, Strand MR. 2003. Haemocytes from Pseudoplusia includens express multiple $\alpha$ and $\beta$ integrin subunits. Insect. Mol. Biol. 12:441-52

188. Williams MJ, Ando I, Hultmark D. 2005. Drosophila melanogaster Rac2 is necessary for a proper cellular immune response. Genes Cells 10:813-23

189. Williams MJ, Wiklund ML, Wikman S, Hultmark D. 2006. Rac1 signaling in the Drosophila larval cellular immune response. F. Cell Sci. 119:2015-24

190. Kurucz E, Zettervall C, Sinka R, Vilmos P, Pivarcsi A, et al. 2003. Hemese, a hemocytespecific transmembrane protein, affects the cellular immune response in Drosophila. Proc. Natl. Acad. Sci. USA 100:2622-27

191. Wertheim B, Kraaijeveld AR, Schuster E, Blanc E, Hopkins M, et al. 2005. Genomewide gene expression in response to parasitoid attack in Drosophila. Genome Biol. 6:R94

192. Rizki RM, Rizki TM. 1980. Hemocyte responses to implanted tissues in Drosophila melanogaster larvae. Roux Arch. Dev. Biol. 189:207-13

193. Crozatier M, Ubeda JM, Vincent A, Meister M. 2004. Cellular immune response to parasitization in Drosophila requires the EBF orthologue collier. PLoS Biol. 2:e196 
194. Sparrow JC. 1978. Melanotic “tumours.” In The Genetics and Biology of Drosophila, ed. M Ashburner, TRF Wright, 2B:277-313. London: Academic

194a. Minakhina S, Steward R. 2006. Melanotic mutants in Drosophila: pathways and phenotypes. Genetics 174:253-63

195. Watson KL, Johnson TK, Denell RE. 1991. Lethal(1) aberrant immune response mutations leading to melanotic tumor formation in Drosophila melanogaster. Dev. Genet. 12:173-87

196. Hanratty WP, Dearolf CR. 1993. The Drosophila Tumorous-lethal hematopoietic oncogene is a dominant mutation in the hopscotch locus. Mol. Gen. Genet. 238:33-37

197. Goto A, Kadowaki T, Kitagawa Y. 2003. Drosophila bemolectin gene is expressed in embryonic and larval hemocytes and its knock down causes bleeding defects. Dev. Biol. 264:582-91

198. Fessler LI, Nelson RE, Fessler JH. 1994. Drosophila extracellular matrix. Methods Enzymol. 245:271-94

199. Reichhart JM, Meister M, Dimarcq JL, Zachary D, Hoffmann D, et al. 1992. Insect immunity: developmental and inducible activity of the Drosophila diptericin promoter. EMBO 7. 11:1469-77

200. Samakovlis C, Asling B, Boman HG, Gateff E, Hultmark D. 1992. In vitro induction of cecropin genes: an immune response in a Drosophila blood cell line. Biochem. Biophys. Res. Commun. 188:1169-75

201. Muta T, Iwanaga S. 1996. The role of hemolymph coagulation in innate immunity. Curr. Opin. Immunol. 8:41-47

202. Söderhäll K, Cerenius L, Johansson MW. 1996. The prophenoloxidase activating system in invertebrates. In New Directions in Invertebrate Immunology, ed. K Söderhäll, S Iwanaga, GR Vasta, pp. 229-53. Fair Haven, NJ: SOS Publ.

203. Scherfer C, Karlsson C, Loseva O, Bidla G, Goto A, et al. 2004. Isolation and characterization of hemolymph clotting factors in Drosophila melanogaster by a pullout method. Curr. Biol. 14:625-29

204. Karlsson C, Korayem AM, Scherfer C, Loseva O, Dushay MS, Theopold U. 2004. Proteomic analysis of the Drosophila larval hemolymph clot. 7. Biol. Chem. 279:5203341

205. Bidla G, Lindgren M, Theopold U, Dushay MS. 2005. Hemolymph coagulation and phenoloxidase in Drosophila larvae. Dev. Comp. Immunol. 29:669-79

206. Nappi AJ, Vass E. 1993. Melanogenesis and the generation of cytotoxic molecules during insect cellular immune reactions. Pigment Cell Res. 6:117-26

207. Ashida M. 1990. The prophenoloxidase cascade in insect immunity. Res. Immunol. 141:908-10

208. Söderhäll K, Cerenius L. 1998. Role of prophenoloxidase-activating system in invertebrate immunity. Curr. Opin. Immunol. 10:23-28

209. Ochiai M, Ashida M. 1999. A pattern recognition protein for peptidoglycan. Cloning the cDNA and the gene of the silkworm, Bombyx mori. F. Biol. Chem. 274:11854-58

210. Ochiai M, Ashida M. 2000. A pattern-recognition protein for $\beta-1,3$-glucan. The binding domain and the cDNA cloning of $\beta$-1,3-glucan recognition protein from the silkworm, Bombyx mori. F. Biol. Chem. 275:4995-5002

211. Ma C, Kanost MR. 2000. A $\beta 1,3$-glucan recognition protein from an insect, Manduca sexta, agglutinates microorganisms and activates the phenoloxidase cascade. F. Biol. Chem. 275:7505-14

212. Lee MH, Osaki T, Lee JY, Baek MJ, Zhang R, et al. 2003. Peptidoglycan recognition proteins involved in 1,3- $\beta$-D-glucan-dependent prophenoloxidase activation system of insect. F. Biol. Chem. 279:3218-27 
213. Braun A, Hoffmann JA, Meister M. 1998. Analysis of the Drosophila host defense in domino mutant larvae, which are devoid of hemocytes. Proc. Natl. Acad. Sci. USA 95:14337-42

214. De Gregorio E, Han SJ, Lee WJ, Baek MJ, Osaki T, et al. 2002. An immune-responsive Serpin regulates the melanization cascade in Drosophila. Dev. Cell 3:581-92

215. Castillejo-Lopez C, Hacker U. 2005. The serine protease Sp7 is expressed in blood cells and regulates the melanization reaction in Drosophila. Biochem. Biophys. Res. Commun. 338:1075-82

216. Leclerc V, Pelte N, El Chamy L, Martinelli C, Ligoxygakis P, et al. 2005. Prophenoloxidase activation is not required for survival to microbial infections in Drosophila. EMBO Rep. 7:231-35

217. Tang H, Kambris Z, Lemaitre B, Hashimoto C. 2006. Two proteases defining a melanization cascade in the immune system of Drosophila. F. Biol. Chem. 281:28097-104

218. Ashburner M, Golic KG, Hawley RS. 2005. Parasites, pests, and diseases. In Drosophila, A Laboratory Handbook, ed. M Ashburner, pp. 1285-333. New York: Cold Spring Harbor Lab. Press. 2nd ed.

219. Vodovar N, Acosta C, Lemaitre B, Boccard F. 2004. Drosophila: a polyvalent model to decipher host-pathogen interactions. Trends Microbiol. 12:235-42

220. Elrod-Erickson M, Mishra S, Schneider D. 2000. Interactions between the cellular and humoral immune responses in Drosophila. Curr. Biol. 10:781-84

221. D'Argenio DA, Gallagher LA, Berg CA, Manoil C. 2001. Drosophila as a model host for Pseudomonas aeruginosa infection. F. Bacteriol. 183:1466-71

222. Flyg C, Kenne K, Boman HG. 1980. Insect pathogenic properties of Serratia marcescens: phage-resistant mutants with a decreased resistance to Cecropia immunity and a decreased virulence to Drosophila. F. Gen. Microbiol. 120:173-81

223. Kurz CL, Chauvet S, Andres E, Aurouze M, Vallet I, et al. 2003. Virulence factors of the human opportunistic pathogen Serratia marcescens identified by in vivo screening. EMBO 7. 22:1451-60

224. Lau GW, Goumnerov BC, Walendziewicz CL, Hewitson J, Xiao W, et al. 2003. The Drosophila melanogaster Toll pathway participates in resistance to infection by the gramnegative human pathogen Pseudomonas aeruginosa. Infect. Immun. 71:4059-66

225. Apidianakis Y, Mindrinos MN, Xiao W, Lau GW, Baldini RL, et al. 2005. Profiling early infection responses: Pseudomonas aeruginosa eludes host defenses by suppressing antimicrobial peptide gene expression. Proc. Natl. Acad. Sci. USA 102:2573-78

226. Chugani SA, Whiteley M, Lee KM, D’Argenio D, Manoil C, Greenberg EP. 2001. QscR, a modulator of quorum-sensing signal synthesis and virulence in Pseudomonas aeruginosa. Proc. Natl. Acad. Sci. USA 98:2752-57

227. Fauvarque MO, Bergeret E, Chabert J, Dacheux D, Satre M, Attree I. 2002. Role and activation of type III secretion system genes in Pseudomonas aeruginosa-induced Drosophila killing. Microb. Pathog. 32:287-95

228. Avet-Rochex A, Bergeret E, Attree I, Meister M, Fauvarque MO. 2005. Suppression of Drosophila cellular immunity by directed expression of the ExoS toxin GAP domain of Pseudomonas aeruginosa. Cell. Microbiol. 7:799-810

229. Dionne MS, Ghori N, Schneider DS. 2003. Drosophila melanogaster is a genetically tractable model host for Mycobacterium marinum. Infect. Immun. 71:3540-50

229a. Dionne MS, Pham LN, Shirasu-Hiza M, Schneider DS. 2006. Akt and FOXO dysregulation contribute to infection-induced wasting in Drosophila. Curr. Biol. 16:1977-85

230. Brandt SM, Dionne MS, Khush RS, Pham LN, Vigdal TJ, Schneider DS. 2004. Secreted bacterial effectors and host-produced Eiger/TNF drive death in a Salmonella-infected fruit fly. PLoS Biol. 2:e418 
231. Rahme LG, Ausubel FM, Cao H, Drenkard E, Goumnerov BC, et al. 2000. Plants and animals share functionally common bacterial virulence factors. Proc. Natl. Acad. Sci. USA 97:8815-21

232. Ewbank JJ. 2002. Tackling both sides of the host-pathogen equation with Caenorbabditis elegans. Microbes Infect. 4:247-56

233. Cheng LW, Portnoy DA. 2003. Drosophila S2 cells: an alternative infection model for Listeria monocytogenes. Cell. Microbiol. 5:875-85

234. Elwell C, Engel JN. 2005. Drosophila melanogaster S2 cells: a model system to study Chlamydia interaction with host cells. Cell. Microbiol. 7:725-39

235. Basset A, Tzou P, Lemaitre B, Boccard F. 2003. A single gene that promotes interactions of a phytopathogenic bacterium with its insect vector, Drosophila melanogaster. EMBO Rep. 4:205-9

236. Muniz CA, Jaillard D, Lemaitre B, Boccard F. 2007. Erwinia carotovora Evf antagonizes the elimination of bacteria in the gut of Drosophila larvae. Cell. Microbiol. 9:106-19

237. Vodovar N, Vinals M, Liehl P, Basset A, Degrouard J, et al. 2005. Drosophila host defense after oral infection by an entomopathogenic Pseudomonas species. Proc. Natl. Acad. Sci. USA 102:11414-19

238. Liehl P, Blight M, Vodovar N, Boccard F, Lemaitre B. 2006. Prevalence of local immune response against oral infection in a Drosophila/Pseudomonas infection model. PLoS Pathog. 2:e56

239. Vodovar N, Vallenet D, Cruveiller S, Rouy Z, Barbe V, et al. 2006. Complete genome sequence of the entomopathogenic and metabolically versatile soil bacterium Pseudomonas entomophila. Nat. Biotechnol. 24:673-79

240. Nappi AJ, Vass E, Frey F, Carton Y. 2000. Nitric oxide involvement in Drosophila immunity. Nitric Oxide 4:423-30

241. Foley E, O'Farrell PH. 2003. Nitric oxide contributes to induction of innate immune responses to gram-negative bacteria in Drosophila. Genes Dev. 17:115-25

242. Clarkson JM, Charnley AK. 1996. New insights into the mechanisms of fungal pathogenesis in insects. Trends Microbiol. 4:197-203

243. Alarco AM, Marcil A, Chen J, Suter B, Thomas D, Whiteway M. 2004. Immunedeficient Drosophila melanogaster: a model for the innate immune response to human fungal pathogens. F. Immunol. 172:5622-28

244. Carton Y, Bouletreau M, van Alphen JJM, van Lenteren JC. 1986. The Drosophila parasitic wasps. In The Genetics and Biology of Drosophila, ed. M Ashburner, HL Carson, JN Thompson, pp. 347-94. New York: Academic

245. Hita M, Espagne E, Lemeunier F, Pascual L, Carton Y, et al. 2006. Mapping candidate genes for Drosophila melanogaster resistance to the parasitoid wasp Leptopilina boulardi. Genet. Res. 88:81-91

245a. Dubuffet A, Dupas S, Frey F, Drezen JM, Poirie M, Carton Y. 2007. Genetic interactions between the parasitoid wasp Leptopilina boulardi and its Drosophila hosts. Heredity. 98:2127

246. Kraaijeveld AR, van Alphen JJM. 1994. Geographical variation in resistance of the parasitoids Asobara tabida against encapsulation by Drosophila melanogaster larvae: the mechanisms explored. Physiol. Entomol. 19:9-14

247. Prevost G, Eslin P, Doury G, Moreau SJ, Guillot S. 2005. Asobara, braconid parasitoids of Drosophila larvae: unusual strategies to avoid encapsulation without VLPs. F. Insect. Physiol. 51:171-79 
248. Eslin P, Prevost G. 2000. Racing against host's immunity defenses: a likely strategy for passive evasion of encapsulation in Asobara tabida parasitoids. F. Insect. Physiol. 46:116167

249. Rizki RM, Rizki TM. 1984. Selective destruction of a host blood cell type by a parasitoid wasp. Proc. Natl. Acad. Sci. USA 81:6154-58

250. Rizki RM, Rizki TM. 1990. Parasitoid virus-like particles destroy Drosophila cellular immunity. Proc. Natl. Acad. Sci. USA 87:8388-92

251. Rizki TM, Rizki RM, Carton Y. 1990. Leptopilina beterotoma and L. boulardi: strategies to avoid cellular defense responses of Drosophila melanogaster. Exp. Parasitol. 70:466-75

252. Labrosse C, Eslin P, Doury G, Drezen JM, Poirié M. 2005. Haemocyte changes in D. melanogaster in response to long gland components of the parasitoid wasp Leptopilina boulardi: a Rho-GAP protein as an important factor. F. Insect. Physiol. 51:161-70

253. Labrosse C, Stasiak K, Lesobre J, Grangeia A, Huguet E, et al. 2005. A RhoGAP protein as a main immune suppressive factor in the Leptopilina boulardi (Hymenoptera, Figitidae)Drosophila melanogaster interaction. Insect. Biochem. Mol. Biol. 35:93-103

254. Chiu H, Morales J, Govind S. 2006. Identification and immuno-electron microscopy localization of $\mathrm{p} 40$, a protein component of immunosuppressive virus-like particles from Leptopilina heterotoma, a virulent parasitoid wasp of Drosophila. F. Gen. Virol. 87:461-70

255. Morales J, Chiu H, Oo T, Plaza R, Hoskins S, Govind S. 2005. Biogenesis, structure, and immune-suppressive effects of virus-like particles of a Drosophila parasitoid, Leptopilina victoriae. 7. Insect. Physiol. 51:181-95

256. Moreau SJ, Eslin P, Giordanengo P, Doury G. 2003. Comparative study of the strategies evolved by two parasitoids of the genus Asobara to avoid the immune response of the host, Drosophila melanogaster. Dev. Comp. Immunol. 27:273-82

257. Brun G, Plus N. 1980. The viruses of Drosophila. In The Genetics and Biology of Drosophila, ed. M Ashburner, TRF Wright, pp. 625-702. New York: Academic

257a. Habayeb MS, Ekengren SK, Hultmark D. 2006. Nora virus, a persistent virus in Drosophila, defines a new picorna-like virus family. F. Gen. Virol. 87:3045-51

258. Contamine D, Petitjean AM, Ashburner M. 1989. Genetic resistance to viral infection: the molecular cloning of a Drosophila gene that restricts infection by the rhabdovirus sigma. Genetics 123:525-33

259. Wayne ML, Contamine D, Kreitman M. 1996. Molecular population genetics of $\operatorname{ref}(2) P$, a locus which confers viral resistance in Drosophila. Mol. Biol. Evol. 13:191-99

260. Wyers F, Petitjean AM, Dru P, Gay P, Contamine D. 1995. Localization of domains within the Drosophila $\operatorname{Ref}(2) \mathrm{P}$ protein involved in the intracellular control of sigma rhabdovirus multiplication. F. Virol. 69:4463-70

261. Cherry S, Perrimon N. 2004. Entry is a rate-limiting step for viral infection in a Drosophila melanogaster model of pathogenesis. Nat. Immunol. 5:81-87

262. Cherry S, Doukas T, Armknecht S, Whelan S, Wang H, et al. 2005. Genome-wide RNAi screen reveals a specific sensitivity of IRES-containing RNA viruses to host translation inhibition. Genes Dev. 19:445-52

262a. Cherry S, Kunte A, Wang H, Coyne C, Rawson RB, Perrimon N. 2006. COPI activity coupled with fatty acid biosynthesis is required for viral replication. PLoS Pathog. 2:e102

263. Sabatier L, Jouanguy E, Dostert C, Zachary D, Dimarcq JL, et al. 2003. Pherokine-2 and -3. Eur. 7. Biochem. 270:3398-407

264. Zambon RA, Nandakumar M, Vakharia VN, Wu LP. 2005. The Toll pathway is important for an antiviral response in Drosophila. Proc. Natl. Acad. Sci. USA 102:7257-62

265. Cherry S, Silverman N. 2006. Host-pathogen interactions in Drosophila: new tricks from an old friend. Nat. Immunol. 7:911-17 
266. Roxstrom-Lindquist K, Terenius O, Faye I. 2004. Parasite-specific immune response in adult Drosophila melanogaster: a genomic study. EMBO Rep. 5:207-12

267. Wang XH, Aliyari R, Li WX, Li HW, Kim K, et al. 2006. RNA interference directs innate immunity against viruses in adult Drosophila. Science 312:452-54

268. Galiana-Arnoux D, Dostert C, Schneemann A, Hoffmann JA, Imler JL. 2006. Essential function in vivo for Dicer-2 in host defense against RNA viruses in Drosophila. Nat. Immunol. 7:590-97

269. Zambon RA, Vakharia VN, Wu LP. 2006. RNAi is an antiviral immune response against a dsRNA virus in Drosophila melanogaster. Cell. Microbiol. 8:880-89

269a. van Rij RP, Saleh MC, Berry B, Foo C, Houk A, et al. 2006. The RNA silencing endonuclease Argonaute 2 mediates specific antiviral immunity in Drosophila melanogaster. Genes Dev. 20:2985-95

270. Obbard DJ, Jiggins FM, Halligan DL, Little TJ. 2006. Natural selection drives extremely rapid evolution in antiviral RNAi genes. Curr. Biol. 16:580-85

271. Jiggins FM, Kim KW. 2005. The evolution of antifungal peptides in Drosophila. Genetics 171:1847-59

272. Choe KM, Lee H, Anderson KV. 2005. Drosophila peptidoglycan recognition protein LC (PGRP-LC) acts as a signal-transducing innate immune receptor. Proc. Natl. Acad. Sci. USA 102:1122-26

273. Hu S, Yang X. 2000. dFADD, a novel death domain-containing adapter protein for the Drosophila caspase DREDD. 7. Biol. Chem. 275:30761-64

274. Stoven S, Ando I, Kadalayil L, Engström Y, Hultmark D. 2000. Activation of the Drosophila NF-kB factor Relish by rapid endoproteolytic cleavage. EMBO Rep. 1:347-52

275. Stoven S, Silverman N, Junell A, Hedengren-Olcott M, Erturk D, et al. 2003. Caspasemediated processing of the Drosophila NF-кB factor Relish. Proc. Natl. Acad. Sci. USA 100:5991-96

276. Sorrentino RP, Melk JP, Govind S. 2004. Genetic analysis of contributions of dorsal group and JAK-Stat92E pathway genes to larval hemocyte concentration and the egg encapsulation response in Drosophila. Genetics 166:1343-56

277. Huang L, Ohsako S, Tanda S. 2005. The lesswright mutation activates Rel-related proteins, leading to overproduction of larval hemocytes in Drosophila melanogaster. Dev. Biol. 280:407-20 


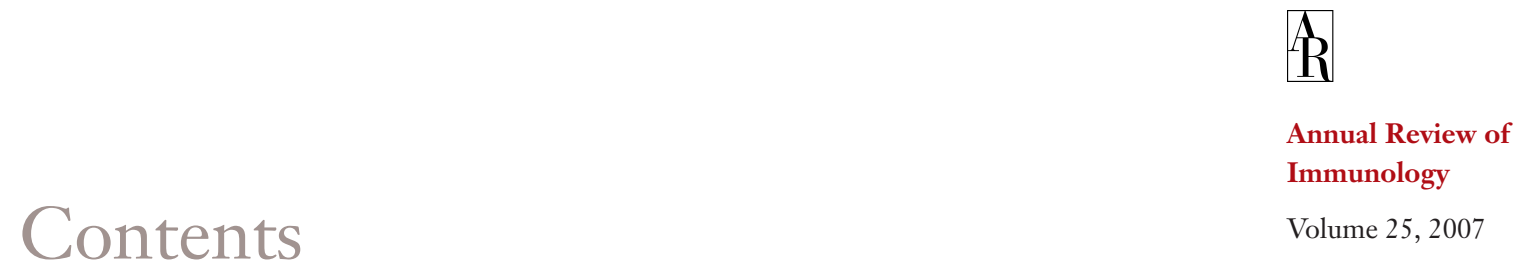

Frontispiece

Peter C. Doherty ..........................................................

Challenged by Complexity: My Twentieth Century in Immunology

Peter C. Doherty ........................................................ 1

The Impact of Glycosylation on the Biological Function and Structure of Human Immunoglobulins

fames N. Arnold, Mark R. Wormald, Robert B. Sim, Pauline M. Rudd, and Raymond A. Dwek

The Multiple Roles of Osteoclasts in Host Defense: Bone Remodeling and Hematopoietic Stem Cell Mobilization

Orit Kollet, Ayelet Dar, and Tsvee Lapidot 51

Flying Under the Radar: The Immunobiology of Hepatitis C

Lynn B. Dustin and Charles M. Rice ...

Resolution Phase of Inflammation: Novel Endogenous

Anti-Inflammatory and Proresolving Lipid Mediators and Pathways

Charles N. Serban

Immunobiology of Allogeneic Hematopoietic Stem Cell

Transplantation

Lisbeth A. Welniak, Bruce R. Blazar, and William 7. Murphy

Effector and Memory CTL Differentiation

Matthew A. Williams and Michael 7. Bevan

TSLP: An Epithelial Cell Cytokine that Regulates T Cell

Differentiation by Conditioning Dendritic Cell Maturation

Yong-7un Liu, Vasilli Soumelis, Noribiko Watanabe, Tomoki Ito,

Yui-Hsi Wang, Rene de Waal Malefyt, Miyuki Omori, Baobua Zhou, and Steven F. Ziegler

Discovery and Biology of IL-23 and IL-27: Related but Functionally

Distinct Regulators of Inflammation

Robert A. Kastelein, Christopher A. Hunter, and Daniel 7. Cua 221 
Improving $\mathrm{T}$ Cell Therapy for Cancer

Ann M. Leen, Cliona M. Rooney, and Aaron E. Foster

Immunosuppressive Strategies that are Mediated by Tumor Cells

Gabriel A. Rabinovich, Dmitry Gabrilovich, and Eduardo M. Sotomayor

The Biology of NKT Cells

Albert Bendelac, Paul B. Savage, and Luc Teyton

Regulation of Cellular and Humoral Immune Responses by the SLAM and SAP Families of Molecules

Cindy S. Ma, Kim E. Nichols, and Stuart G. Tangye

Mucosal Dendritic Cells

Akiko Iwasaki ....

Immunologically Active Autoantigens: The Role of Toll-Like

Receptors in the Development of Chronic Inflammatory Disease

Ann Marshak-Rotbstein and Ian R. Rifkin

The Immunobiology of SARS

Jun Chen and Kanta Subbarao

Nonreceptor Protein-Tyrosine Phosphatases in Immune Cell Signaling Lily I. Pao, Karen Badour, Katherine A. Siminovitch, and Benjamin G. Neel

Fc Receptor-Like Molecules

Randall S. Davis

The Death Domain Superfamily in Intracellular Signaling of Apoptosis and Inflammation

Hyun Ho Park, Yu-Chib Lo, Su-Chang Lin, Liwei Wang, Fin Kuk Yang, and $\mathrm{Hao} \mathrm{Wu}$

Cellular Responses to Viral Infection in Humans: Lessons from

Epstein-Barr Virus

Andrew D. Hislop, Grabam S. Taylor, Delphine Sauce, and Alan B. Rickinson ......587

Structural Basis of Integrin Regulation and Signaling

Bing-Hao Luo, Christopher V. Carman, and Timothy A. Springer

Zoned Out: Functional Mapping of Stromal Signaling

Microenvironments in the Thymus

Howard T. Petrie and Juan Carlos Zúniga-Pflücker

T Cells as a Self-Referential, Sensory Organ

Mark M. Davis, Michelle Krogsgaard, Morgan Huse, Fobannes Huppa,

Bjoern F. Lillemeier, and Qi-jing Li

The Host Defense of Drosophila melanogaster

Bruno Lemaitre and Fules Hoffmann 
Ontogeny of the Hematopoietic System Ana Cumano and Isabelle Godin

Chemokine:Receptor Structure, Interactions, and Antagonism Samantha 7. Allen, Susan E. Crown, and Tracy M. Handel ....

IL-17 Family Cytokines and the Expanding Diversity of Effector T Cell Lineages

Casey T. Weaver, Robin D. Hatton, Paul R. Mangan, and Laurie E. Harrington ...821

\section{Indexes}

Cumulative Index of Contributing Authors, Volumes 15-25 ...................853

Cumulative Index of Chapter Titles, Volumes 15-25 .......................... 860

\section{Errata}

An online log of corrections to Annual Review of Immunology chapters (if any, 1997 to the present) may be found at http://immunol.annualreviews.org/errata.shtml 